\title{
Servicio público, actividad económica y competencia. ¿Presenta especificidades la esfera local? ${ }^{1}$
}

\author{
Elisenda Malaret García \\ Catedrática de Derecho Administrativo
}

SUMARIO: I. ESTADO Y ACTIVIDAD ECONÓMICA: UNA PRESENTACIÓN. II. SERVICIO PÚBLICO Y ACTIVIDAD ECONÓMICA: UNA DICOTOMÍA APARENTE, LA REALIDAD DE LOS SERVICIOS PÚBLICOS ECONÓMICOS. III. SERVICIOS DE INTERÉS GENERAL Y SERVICIOS DE INTERÉS ECONÓMICO GENERAL: DOS NOCIONES PROPIAS DEL DERECHO COMUNITARIO. IV. LA DISTINCIÓN ENTRE SERVICIOS PÚBLICOS ECONÓMICOS Y SERVICIOS NO ECONÓMICOS, UNA DISTINCIÓN PRESENTE EN EL DERECHO POSITIVO ESPAÑOL, UNA DIFERENCIACIÓN DOTADA DE SIGNIFICACIÓN PRÁCTICA. UNA DISTINCIÓN TÍPICA EN EL DERECHO LOCAL DE LOS SERVICIOS PÚBLICOS. V. UNA DISTINCIÓN TRADICIONAL EN EL DERECHO ADMINISTRATIVO FRANCÉS, UNA DISTINCIÓN RELACIONADA CON LA PRESENTACIÓN DOCTRINAL DE LA CRISIS DEL SERVICIO PÚBLICO. VI. LA DISTINCIÓN EN EL DERECHO COMUNITARIO Y SU VINCULACIÓN CON UNA APELACIÓN DEL TJCE A LA LEGITIMACIÓN DEMOCRÁTICA NACIONAL. VII. LA INFLUENCIA DE LA JURISPRUDENCIA COMUNITARIA SOBRE LOS DERECHOS NACIONALES: LA EMERGENCIA DE UNA NUEVA ARTICULACIÓN DE LOS INTERESES GENERALES (O COLECTIVOS) Y LA LIBERTAD DE EMPRESA. VIII. A MODO DE CONCLUSIONES.

\section{ESTADO Y ACTIVIDAD ECONÓMICA: UNA PRESENTACIÓN}

Puede causar sorpresa ocuparse del servicio público en un trabajo escrito en homenaje al Profesor Sebastián MarTín-Retortillo, bien conocido es el escepticismo que mostraba en torno a la posibilidad de identificar de manera certera esta categoría singularizadora de determinadas tareas públicas. Quizás el recurso a una noción que él había utilizado de

\footnotetext{
${ }^{1}$ Este trabajo elaborado expresamente como homenaje al Profesor Sebastián MARTín-RETORTILLO presenta algunos resultados de la investigación desarrollada en el marco del proyecto «Gobierno y Administración en el proceso de integración europea: los retos del Estado regulador» (BJU 2001-03151), algunas de las consideraciones fueron inicialmente expuestas en el artículo «Servizio pubblico e attività economica» publicado en la obra colectiva A. BRANCASI (dir.): Liberalizzazione del transporto terrestre e Servizi pubblici economici, Il Mulino, Bologna, 2003.
} 
manera muy fértil, la de supraconcepto ${ }^{2}$, hubiera permitido vencer este distanciamiento; un posicionamiento que tenía también mucho que ver con una actitud que mezclaba un permanente acicate intelectual para conocer, para desentrañar lo fundamental, para ir a la raíz de los problemas con un pragmatismo que le alejaban de construcciones demasiados dogmáticas ${ }^{3}$, carentes de significación práctica. «Hay que introducir una cierta dosis de relativismo frente a la orquestación que con frecuencia se hace del fenómeno privatizador. La realidad es siempre mucho más matizada», son palabras suyas recientes, pronunciadas en la vieja Facultad de Derecho de Coimbra en abril del $2000^{4}$. Si el Derecho es siempre la búsqueda del equilibrio, ello todavía está más presente en una concepción del Derecho administrativo que se concibe como articulación de las garantías de los derechos particulares (que provocan la limitación y el control) y la necesaria eficacia del quehacer estatal (que suscitan la concesión de privilegios y garantías), una visión del Derecho administrativo que tan bien plasmó en su momento el libro de WeIL ${ }^{5}$.

Pero los servicios públicos no son ajenos a su labor investigadora, ahora no podemos reseñarlo con detenimiento, éste no es el objeto de este trabajo. Pretendemos analizar y discutir algunas de las tesis manejadas por la doctrina española de los últimos años, al socaire del proceso de integración europea. Así se ha sostenido que el concepto de servicio público ya no era adecuado, para posteriormente añadir que nacía un nuevo servicio público ${ }^{6} \mathrm{o}$ casi paralelamente, que ahora la noción fundamental es la de servicios esenciales ${ }^{7}$ o en otra dirección parece que se ha postulado que los objetivos de solidaridad propios de los servicios públicos se plasmen ahora como servicios de interés general ${ }^{8} \mathrm{y}$

\footnotetext{
${ }^{2}$ Vid. su conocido estudio El Derecho Civil en la génesis del Derecho Administrativo y de sus instituciones IGO, Sevilla, 1960, publicado de nuevo como capítulo de un libro que lleva el mismo título, Civitas, Madrid, 1996, p. 54 y ss. (citamos por la última versión).

${ }^{3} \mathrm{O}$ «demasiado retóricas conceptualmente», como expresamente afirma en el prólogo a la nueva edición de sus trabajos citado en la nota anterior.

${ }^{4}$ Recogidas en su ponencia presentada en el IV Congreso Luso-Español de Derecho Administrativo.

${ }^{5}$ Traducido por primera vez al castellano en 1966 por editorial Taurus.

${ }^{6}$ Vid. el conjunto de trabajos publicados colectivamente por G. Ariño, M. De La Cuétara, J.L Martínez López-Muñiz: El nuevo servicio público, Marcial Pons, Madrid, 1997
}

${ }^{7}$ Vid. J.L. Martínez LóPEZ-MuñIZ, una presentación resumida de su posición en «Servicio público, servicio universal y obligación de servicio público en la perspectiva del Derecho comunitario: los servicios esenciales y sus regímenes alternativos», ponencia en el IV Congreso Luso-Español de Derecho Administrativo, Coimbra, 2000. ${ }^{8}$ Parece moverse en esta dirección T. de la QUADRA-SALCEDO, vid. «Servicios públicos versus ser-
vicios de interés general tras el Tratado de Ámsterdam», Aranzadi, junio 1998. 
en otros supuestos se alude al final del servicio público y se proclama la irrupción de los servicios de interés general ${ }^{9}$. Como no compartimos estas aproximaciones que, si bien es cierto que suponen un fuerte debate en torno al papel del Estado en la economía especialmente, pero también en la sociedad aunque sorprendentemente ello parece encuadrarse en otro debate de conceptos, entendemos que el modo en que ha sido abordado acaba convirtiendo la discrepancia en una cuestión puramente nominalistica. Quizás es un eco de la manera de abordar esta cuestión en nuestra tradición, como un debate de conceptos en el que la jurisprudencia y los casos que resolvía han sido los grandes ausentes; en mi opinión ello ha supuesto una falta de versatilidad, de plasticidad de la discusión dogmática que ha adquirido un tono demasiado libresco. Un debate en el que los conceptos no se vinculan necesariamente a la resolución de problemas prácticos, lo que convierte en muy difícil el diálogo.

Nosotros partimos de una concepción más apegada a la realidad del quehacer de la pluralidad de Administraciones Públicas, una visión que toma en consideración el conjunto de las actividades prestacionales de los distintos niveles territoriales de Gobierno y Administración. Por ello entendemos que sólo cuando se parte de la premisa que servicio público y monopolio o reserva son inescindibles ${ }^{10}$ —el denominado «servicio público en sentido estricto que siempre requiere la denominada publicatio»-, después debe acudirse al artificio de crear una nueva categoría que permita dar cuenta de toda aquella gama de servicios que la Administración Pública suministra por ella misma o encomienda a terceros sin que exista monopolio alguno. No es ésta nuestra concepción, lo fundamental es la asunción de las tareas como cometidos propios de la Administración, lo que supone entender que en principio la actividad de la Administración es servicio público (sólo excepcionalmente no tendrá este carácter), la cuestión se planteará en el análisis de la actividad desarrollada por el particular, entonces para delimitar la actividad de servicio público de la de policía deberemos examinar el vínculo con la Administración, si existe o no una encomienda o delegación de la Administración. Ello supone aceptar como premisa de partida que no toda la actividad deba tener necesariamente la misma consideración jurídica; la misma actividad realizada por los particulares en libre desarrollo de su personalidad no debe ser

\footnotetext{
${ }^{9}$ Vid. especialmente S. GonZÁLEZ-VARAs: Los mercados de interés general: telecomunicaciones y postales, energéticos y de transportes, Comares, Granada, 2001.

${ }^{10} \mathrm{Vid}$., por todos, la equiparación entre servicio público y reserva, T. De La Quadra-SALCEDo: Corporaciones locales y actividad económica, Marcial Pons, 1999, p. 45.
} 
considerada servicio público aunque esté sometida a un control administrativo ${ }^{11}$.

Este trabajo pretende pues demostrar que no hace falta acudir a nuevas categorías, recurrir a otras denominaciones, transportar el nomenclátor acuñado en otros sistemas normativos, que lo que si hay que hacer es determinar con precisión el contexto normativo en el que se desarrollan las actividades públicas, examinando con detenimiento los fines perseguidos y las relaciones con los ciudadanos-usuarios. No se trata sólo de examinar la posición de las empresas. En el ámbito de los servicios públicos, la gestión privada o la gestión de acuerdo con el Derecho de la competencia tienen un carácter instrumental, mejorar la eficiencia, pero no son un fin en sí mismo, la finalidad fundamental es garantizar la equidad. Si bien la preservación de la actividad privada, de la concurrencia y en su caso de la competencia, ha estado siempre presente, como bien recoge la legislación local española, lo que no puede obviarse es que esta legislación fue alumbrada en períodos poco receptivos a la libertad de empresa y a las libertades en general. La legislación local post-constitucional ha intentado rediseñar el modelo pero quizás ha estado poco acertada en el diseño de la sistemática y en el lenguaje utilizado, el debate doctrinal no parece haber acompañado la necesaria tarea de interpretación y sistematización al haber discurrido por otros cauces más propios de presentación de alternativas de modelos regulatorios, o quizás de cambios en la manera de concebir las relaciones entre el estado y los ciudadanos.

Hace ya un tiempo Martín-Retortillo y Salas iniciaban el análisis de un ámbito de intervención económica del Estado de enorme raigambre en Europa, el monopolio de tabacos, con una afirmación que nos parece muy pertinente para adentrarse no sólo en la complejidad de las relaciones entre Estado y Economía, sino sobre todo para comprender mejor las dificultades que muchas veces la doctrina española ha expresado en la configuración dogmática del concepto de servicio público. Éstas eran sus palabras: «no es necesaria ninguna especial investigación para poder descubrir el trasfondo económico que existe en no pocas de las instituciones jurídicas actualmente vigentes» ${ }^{12}$. Este criterio es fundamental en el análisis de las instituciones, de las reglas que disciplinan el quehacer económico del

\footnotetext{
${ }^{11}$ Un desarrollo en E. MaLARET: «Administración Pública y servicios públicos: la creación de una red de servicios sociales a los ancianos en la transformación del Estado de bienestar, en AAVV: Los servicios sociales de atención a la tercera edad, Tirant Lo Blanch, Valencia, 2002.

${ }^{12}$ El monopolio de tabacos. Aspectos jurídicos de su organización y explotación, Madrid, 1969, p. 7 .
} 
Estado y requiere en consecuencia prestar atención a las aportaciones de las distintas Ciencias sociales y muy especialmente la Economía, no para trasladar miméticamente los instrumentos y las herramientas analíticas y conceptuales al campo del Derecho, sino para comprender mejor y analizar con mayor rigor las transformaciones que se producen. Y, así, estar en condiciones de satisfacer de manera renovada los postulados propios del Estado social y democrático de Derecho que guían la tarea de todo jurista.

\section{Dos aspectos nos interesan}

En primer lugar, el más general que atañe al contexto, al marco de los cambios en la intervención del Estado en la economía. En aquel entonces la economía española conocía los primeros y tímidos momentos de un proceso de liberalización ${ }^{13}$ después de un largo y oscuro período de autarquía y férreo control de la actividad de las empresas, situación esta última que muy bien podemos caracterizar de la mano de Villar Palasí y su conocida propuesta de concesión industrial; es difícil encontrar una mejor caracterización de las barreras jurídicas que impedían el desarrollo de la actividad económica privada, protegiendo a aquellos que ya estaban dentro, proceso que no parece que estuviera guiado por criterios de interés general. Precisamente Martín-Retortillo y SAlas retomaban unas palabras vertidas en un trabajo anterior destacando cómo el mantenimiento de determinadas situaciones de monopolio de hecho o de Derecho suponían un privilegio evidente que acentuaba lo que ya representaba un sistema dirigido a impedir o restringir la competencia, era preciso «restablecer el equilibrio destruido por la desaparición del interés público que es el interés de todos, el interés de la comunidad, no el de los grupos particularizados» ${ }^{14}$; posteriormente daban cuenta de un opúsculo anónimo en el que se defendía la continuidad del monopolio gestionado por una empresa privada ${ }^{15}$. Entonces y ahora también, algunas voces recurren a la idea del servicio público para amparar el monopolio de gestión privada, postulando la privatización pero sin mercado, sin competencia; es verdad que como alguna vez se ha señalado el monopolio se puede definir como la vida tranquila.......Cuando así se opera el servicio deja de estar al servi-

\footnotetext{
${ }^{13}$ Vid. una presentación sintética del debate en aquel momento, E. MaLARET: Régimen jurídicoadministrativo de la reconversión industrial, con prólogo de S. Martín-Retortillo, Civitas, Madrid, 1991, p. 99.

${ }^{14}$ Op. cit., pp. 11 y 12.

${ }^{15}$ Op. cit., p. 16.
} 
cio del público, de la colectividad y se coloca al servicio del interés privado ${ }^{16}$.

Aquel tímido y muy embrionario proceso de liberalización y de apertura de los mercados nacionales generaba dudas y perplejidades. Ahora también. Y entonces como ahora en determinados círculos se tiende a confundir el reconocimiento del papel que juega el mercado en la asignación eficiente de los recursos con un laisser faire, laiser passer; una brillante consigna, un buen eslogan político, pero los historiadores económicos nos han enseñado que éste no ha sido precisamente el criterio rector de las relaciones Estado-economía, no ha existido una manera «natural» de desenvolverse el tráfico económico.

Veamos ahora la singularidad del tipo de actividad analizada en el libro de Martín-Retortillo y Salas que nos sirve de guía en esta presentación del marco de nuestro trabajo, los tabacos. Los tabacos, como la pólvora, el aguardiente y algunos otros productos, se configuran a partir del siglo XVII en distintos países europeos como productos excluidos del tráfico comercial ordinario, como monopolios; las razones son de distinta índole y si bien motivos de orden fiscal o de rentas para la Corona están presente no pueden tampoco desdeñarse los de carácter moral e incluso sanitario-policial. Las formas concretas de producción y explotación han sido varias ${ }^{17}$, seguramente muy deudoras de las distintas tradiciones ideológico-institucionales, de la distinta manera de concebir las relaciones entre los individuos y el Estado que se han ido construyendo a partir de las Ilustraciones que afloraron en Europa ${ }^{18}$. Como bien sabemos, quizás la escocesa y la germánica constituyen los dos modelos más alejados.

Pues bien, en la actualidad, como consecuencia de los cambios acaecidos en la consideración de las tareas del Estado en la economía, en la consideración de los valores y contenidos de lo público, los tabacos no sólo han perdido su consideración de monopolios fiscales ${ }^{19}$, sino que las medidas fiscales que los atañen se diseñan en orden a desincentivar su consumo.

\footnotetext{
${ }^{16} \mathrm{El}$ actual marco legal de la televisión en España suministra un buen ejemplo de esta manera de proceder.

${ }^{17}$ Martín-Retortillo/Salas dan cuenta de la diferencia entre el modelo francés que se implantó a partir del s. XIX y el modelo español que se adopta en el mismo período; gestión pública el primero, privada el segundo.

${ }^{18}$ Vid., entre otros, E. MALARET: «Les fondements du droit public moderne. Conclusions», REDP, 1998, número especial.

${ }^{19}$ Nótese cómo desde los inicios el TCE expresamente consideraba este tipo de monopolios comerciales como contrario a las reglas del propio Tratado.
} 
Esta transformación ilustra de manera muy significativa cómo la delimitación de lo público y lo privado constituyen un continuo devenir. La esfera de las funciones colectivas, de las actividades asumidas por la colectividad tiene un alcance muy distinto, no sólo por razones de orden ideológico sino también por consideraciones de índole temporal y territorial.

Y si convenimos que el interés general, el bien común, la utilidad pública tienen un contenido fluido, la línea de demarcación entre las distintas esferas no sólo no siempre es nítida, sino que es variable en función de las necesidades colectivas o sociales, y sobre todo en función de la manera en que éstas son percibidas por la comunidad en un determinado territorio, entonces podemos también convenir que el contenido de las categorías y conceptos que el Derecho ha creado para aprehender las tareas estatales también cambia.

Como la libertad y el derecho de propiedad se han enriquecido con el desarrollo de nuestras sociedades, nuevas libertades y nuevas propiedades se añaden a la matriz inicial, nuevos ámbitos en las que éstas se ejercen, pues bien, también la policía y el servicio público, las dos categorías alumbradas para describir y prescribir el régimen de las funciones públicas ven como sus contenidos cambian, se modula el alcance de su fuerza y valor jurídico; emergen nuevas policías (alimentaria e incluso científica), desaparecen algunas de las viejas (costumbres) y aparecen nuevos servicios públicos (informacionales, atención a personas maltratadas), se eliminan algunos antiguos; ello supone cambios en las formas organizativas, reconocimiento de nuevos espacios de decisión a los profesionales, a los expertos ${ }^{20}$. Pero las reglas y principios fundamentales permanecen puesto que son inherentes a la especificidad de lo público, régimen jurídico básico al servicio de la articulación y garantía de los distintos derechos y libertades en presencia.

\section{SERVICIO PÚBLICO Y ACTIVIDAD ECONÓMICA: UNA DICOTOMÍA APARENTE, LA REALIDAD DE LOS SERVICIOS PÚBLICOS ECONÓMICOS}

¿Puede una actividad económica ser considerada también un servicio público? ¿Las Administraciones Públicas españolas desarrollan actividades económicas que no tienen el carácter de servicio público? ¿Existen actividades asumidas por la colectividad como la producción y distribución de tabacos para las cuales se hace difícil una configuración jurídica

${ }^{20}$ A veces enunciados como autorregulación regulada, o mejor autorregulación inducida. 
de la actividad en términos de servicio público? ¿Pueden las Administraciones Públicas españolas en el marco de sus competencias optar entre crear un servicio público y ejercer la iniciativa pública en la economía?

Todo un conjunto de cuestiones que exigen una respuesta matizada y que no pueden en ningún momento desconocer la posición jurídica peculiar de la Administración Pública; su especificidad frente a los privados. Su sometimiento a la ley y al Derecho al servicio objetivo de los intereses generales (art. 103.1 CE). Porque la Administración está al servicio del público, al servicio de los intereses colectivos está sometida a determinada disciplina, a determinadas vinculaciones; la Administración tiene obligaciones frente a las que los ciudadanos, los usuarios tienen derechos. La encomienda de algunas de sus tareas, la delegación de algunas funciones, la imposición de obligaciones de servicio público a terceros, la asignación del servicio universal a unos operadores privados, no puede nunca suponer la desvinculación a un régimen jurídico que tiene precisamente su fundamento en el carácter servicial de la Administración; por ello en estos casos los particulares están sometido a un régimen distinto en sus relaciones con los usuarios, un régimen dominado por los principios de continuidad, igualdad y mutabilidad.

Veamos algunas consideraciones previas que nos suministran elementos de análisis y nos permiten desmitificar el alcance de algunos cambios legales recientes. Operación de realismo tanto más pertinente cuanto nuestra tradición tiene consagrada en la legislación positiva una gran variedad de fórmulas de asociación de los particulares a la gestión de los servicios públicos. Quizás debamos adecuar el marco conceptual a la realidad para poder analizar qué funciona y qué no funciona en este diseño tan flexible.

Actividad económica y servicio público. Dos nociones que parecen remitir a órdenes conceptuales distintos, hasta tal punto que cabe preguntarse si en realidad no expresan dinámicas regidas por lógicas contrapuestas: la lógica del interés general frente a la lógica del lucro, y por ello vinculadas o al Estado o al mercado y disciplinadas o por el Derecho público o por el privado.

En realidad y a pesar de que se presenten a menudo en clave de oposición dialéctica, probablemente debido a su distinta legitimación, los puntos de conexión han estado siempre presentes, sobre todo si pensamos en las actividades que permiten interconectar las diversas partes del territorio y que sirven a la circulación de las personas y al transporte de mercancías. Los servicios, las infraestructuras que les dan soporte tienen a menudo una naturaleza colectiva que deriva del carácter indivisible de la prestación o del hecho de que la utilización por parte de un sujeto tenga efectos positi- 
vos sobre el conjunto de la comunidad; ello ocurre con frecuencia con relación a los servicios vinculados al territorio y al desarrollo económico. Satisfacer las necesidades de la comunidad no fue una preocupación ausente en la Roma de Augusto como tampoco lo fue el aumentar la regularidad y la eficiencia de las infraestructuras de la época, especialmente de aquellas destinadas a abastecer de agua las ciudades ${ }^{21}$.

Así pues, los servicios públicos destinados a garantizar el desarrollo económico y a permitir el funcionamiento del mercado han ido siempre de la mano de la propia existencia del mercado. Sin embargo, su papel y su valor han sufrido transformaciones paralelamente al distinto papel que el mercado iba asumiendo. Los cometidos atribuidos a las ciudades traen causa de esta evolución histórica ${ }^{22}$.

Esta vinculación directa entre determinadas infraestructuras soporte de la prestación de determinados servicios, entre servicios públicos y actividad económica permite explicar por qué la economicidad de estos servicios y su eficacia desde el punto de vista de la asignación de los recursos sea más relevante que en los servicios públicos vinculados a las necesidades personales o a la lucha contra los riesgos que el desarrollo social pueda producir (pobreza, enfermedades, desempleo, carencia de hogar, etc.). En estos últimos, la equidad es el valor determinante.

Los cambios en curso de los últimos años, relativos a la disciplina jurídica de las actividades económicas, eliminando obstáculos y barreras para la realización de un alto grado de competencia entre operadores no han dejado de lado aquellas actividades que en el pasado habían estado sometidas a un estrecho control y dirección por parte de la Administración por las utilidades públicas que generaban (public utilities) o a una gestión pública directa. Los servicios públicos económicos o los servicios con un alto valor económico son aquellos más directamente sometidos a las nuevas regulaciones.

Hasta el momento no hemos precisado el sentido jurídico de la noción de servicio público. Más adelante volveremos sobre ello. Ahora queremos tan sólo acercarnos a una realidad siempre presente de forma latente pero a menudo no caracterizada jurídicamente. La realidad de la diversidad de los servicios públicos, ya sean industriales o de beneficencia, económicos o sociales (en sentido amplio), comerciales, asistenciales o simplemente solidarios. La intuición con relación al diverso objeto de la actividad de

\footnotetext{
${ }^{21}$ V.A.M. RAMIERI, I servizi pubblici, Roma, Quasar/Museo della civiltà romana, 1996.

${ }^{22}$ Vid., por todos, F. Braudel, La dinamica del capitalismo (edición italiana), Il Mulino, Bologna, 1988.
} 
prestación ha estado presente en la literatura jurídica española más reciente ${ }^{23}$, diversidad de contenido de la prestación que ofrece algunas claves para la lectura de la diversidad de régimen jurídico pero que no ha sido objeto de un análisis detenido ${ }^{24}$. Sorace avanzó, hace ya algún tiempo, la idea de que el carácter estandarizado de las prestaciones era un aspecto relevante de la especificidad de los servicios económicos ${ }^{25}$.

Estas transformaciones hacen emerger nuevos conceptos y nuevas palabras: servicios esenciales, servicio universal, servicios de base. A menudo las novedades son más aparentes que reales y lo que ha cambiado es más bien el plano sobre el que dichas categorías se mueven y la fuerza que éstas han adquirido en la representación jurídica.

Nosotros partimos de la premisa de que los servicios públicos económicos, los servicios públicos empresariales y los servicios de interés económico general han constituido siempre una especificidad dentro de los deberes de reglamentación, organización (utilizando las dos nociones en sentido amplio) de los poderes públicos; y expresamente recurrimos a la idea de deber para expresar la responsabilidad de los poderes públicos en aras de la efectiva realización de la actividad, al carácter de obligación de la prestación del servicio. Es cierto que esta especificidad no se ha traducido siempre en categorías jurídicas claras ni en un régimen jurídico dotado de una singularidad fuerte, se trataba de una realidad escondida y sin visibilidad, aunque siempre presente de forma latente en el debate jurídico. No debe olvidarse que en la doctrina jurídica española se está aún lejos de haber alcanzado conclusiones que sean compartidas por todos, especialmente si atendemos al dato singular de que el debate sobre los servicios públicos y sus transformaciones sólo se ha centrado en los de carácter económico, es cierto que éstos constituyen el campo de los desmonopolizados; pero, entonces, ¿que ocurre con los otros, los propios del Estado de bienestar? ${ }^{26}$. En este contexto las diferencias que caracteri-

\footnotetext{
${ }^{23}$ Vid., por todos, que los cita de manera bastante completa, M. VAQUer CABALlería: La acción social (Un estudio sobre la actualidad del Estado de Derecho), Tirant lo Blanch, Valencia, 2002.

${ }^{24}$ Con la salvedad del trabajo de M. VAQUER citado anteriormente. Este autor fundamenta en esta distinción las diferencias de régimen jurídico que a partir de la propia Constitución ya se diseñan.

${ }^{25}$ D. SORACE: «Servizi pubblici e servizi (economici) di pubblica utilità», en Diritto pubblico 1999, 2, p. 375.

${ }^{26}$ Quizás ayude a comprender el estado de la cuestión en la doctrina española introducir una nueva referencia terminológica, la de «actividad material o técnica», estos servicios técnicos que las ciudades inglesas pasaron a gestionar para abordar los problemas de concentración urbana que el rápido desarrollo industrial agudizaba en un proceso muy bien analizado por E. GARCíA DE ENTERRíA: «La actividad industrial y mercantil de los municipios», RAP, 1955, p. 17.
} 
zan los servicios que denominamos económicos son un factor de gran problematicidad, sobre todo si no se adopta un criterio claro para hacer visible las profundas diferencias entre unos y otros. Diversidad también dentro del complejo de los servicios públicos económicos que no puede ocultar la especificidad de estos últimos dentro del conjunto total de servicios públicos.

La falta de toma de conciencia de las profundas diferencias que atraviesan la realidad de los servicios públicos y la correlativa necesidad de identificar aquellos hechos estilizados que supongan la caracterización jurídica de dicha realidad para así poderla someter a un régimen jurídico adecuado explica la perplejidad que manifiesta un sector doctrinal. Sector que a menudo valora negativamente la asunción de nuevas responsabilidades por parte de los poderes públicos, tal vez porque razona en términos de «naturaleza de las cosas».

El problema radica en que, si ya es difícil identificar —en cuanto tales- a los servicios económicos, el resto de servicios se presentan simplemente como aquellos que no son económicos. Identificación en clave negativa que evidencia claramente los problemas. Identificación en clave negativa que en la actualidad no puede desvincularse del contexto en el cual se produce, que es aquél del Derecho de la competencia (comunitario fundamentalmente puesto que no existe hasta la fecha disciplina específica de carácter nacional).

Si los servicios económicos han existido siempre y siempre se ha planteado la cuestión de cómo caracterizarlos con carácter general, más allá del casuismo, la novedad de las recientes transformaciones reside en el distinto modo de comportarse en relación con el mercado - más allá del respeto a la iniciativa privada-, así como también en el distinto modo de conciliar el interés general con la eficiencia en la asignación de los recursos. Esta nueva articulación puede tal vez venir expresada por medio de nuevos términos y exigir quizás nuevos conceptos. O quizá si los planos son distintos a lo mejor es más pertinente en orden a la garantía de los derechos en presencia - protección de las empresa vs. protección de los usuarios-operar con conceptos diferentes que permitan evidenciar la diversidad de matices, la articulación del Derecho nacional con el Derecho comunitario.

Servicios públicos económicos que ciertamente son tales porque suponen formas de prestación o de gestión que se aproximan a las que son típicas de la empresa privada. Por ello presentan una relación con el mercado y con la regla que lo regula, la competencia. Son servicios públicos que en mayor o menor medida deberán tomar en consideración la igualdad entre 
todos los operadores. Los poderes públicos deberán establecer la medida concreta de este respeto al entorno concurrencial ${ }^{27}$.

Servicios públicos empresariales que se presentan como tales cuando los poderes públicos no han tomado la decisión esencial de prestarlos gratuitamente, cuando por razones de equidad o eficiencia prefieren que jueguen un cierto papel los mecanismos de mercado.

Utilizamos expresamente como equivalentes para calificar unos determinados servicios públicos tanto la locución «económico» como «empresarial», no sólo por sintonía con la jurisprudencia del TJCE que define como «empresa aquella unidad que desarrolla tareas económicas», sino porque, como veremos luego, en nuestro Derecho esta equiparación también ha estado y sigue presente.

Como veremos, los criterios utilizados por la jurisprudencia comunitaria (que presenta muchas similitudes con la francesa) para calificar una determinada actividad como servicio económico de interés general presentan una cierta circularidad. No se sabe si la forma de gestión, el modo de prestación, el régimen jurídico del personal, las relaciones con los usuarios, la forma y los criterios de financiación son los específicamente exigidos por el tipo de actividad, esto es, porque la actividad es económica o, por el contrario, es la actividad la que se califica como económica porque es gestionada de tal forma y sometida a dicho régimen jurídico.

Nosotros los juristas sabemos que las distinciones y las clasificaciones son convencionales. Se trata de construcciones, no responden a una realidad ontológicamente considerada. Esta consideración es particularmente relevante en el debate sobre los servicios públicos. Permite entender -así como relativizar y normalizar- el hecho de que en el mismo sector de actividad - funcionalmente considerado- podamos encontrar servicio público, según el perfil considerado o la persona jurídica que actúa y servicios que materialmente reúnen las mismas características y no lo son.

El perímetro de los servicios públicos presenta en consecuencia una geometría variable. Las necesidades son diversas dado que el desarrollo económico y social no es el mismo. La estructura de las empresas, la capacidad de las organizaciones non profit, los fallos del mercado o del sector no lucrativo presentan tantas diferencias como diferentes han sido las evo-

\footnotetext{
${ }^{27}$ Vid., la excelente presentación del estado de la cuestión en la actualidad. Así como los factores esenciales de períodos inmediatamente anteriores, en Conseil d'État: Collectivités publiques et concurrence, Rapport public 2002, La documentation française, Paris, 2002.
} 
luciones históricas. Como diferentes son las necesidades y, sobre todo, las valoraciones.

La teoría económica de los bienes públicos, de las esternalidades, de los fallos de mercado así como también de la distinta aproximación a la crisis del Estado proporcionan muchos elementos de reflexión y de análisis y sugieren algunas líneas de reconstrucción para establecer unas bases renovadas sobre las que fundamentar la construcción de los fundamentos de la intervención pública de tipo regulativo pero también prestacional. Por lo tanto, se trataría de una reconstrucción de las funciones de los poderes públicos y de su financiación sobre bases que garanticen una mayor probabilidad de que ésta resulte útil.

\section{SERVICIOS DE INTERÉS GENERAL Y SERVICIOS DE INTERÉS ECONÓMICO GENERAL: DOS NOCIONES PROPIAS DEL DERECHO COMUNITARIO}

Los servicios de interés general representan un factor esencial del modelo europeo de sociedad. Hoy esta idea puede encontrarse en numerosos documentos comunitarios, y no es casualidad que precisamente con una referencia de este tipo se inicie la última comunicación de la Comisión sobre Servicios de interés general en Europa. ${ }^{28}$ Intuitivamente se puede concebir una cierta representación de qué deba entenderse por estos servicios de interés general, dado que la idea de su centralidad está presente en todos los sistemas jurídicos de la Unión, a pesar de que también por sus distintas tradiciones constitucionales sean profundas las divergencias con relación a las ordenaciones institucionales, a las concepciones y a las teorías jurídicas, a las relaciones Estado-sociedad, a la distribución de obligaciones entre Administración y mercado, a las culturas jurídicas, a las formas de intervención pública.

Servicios de interés general que en el Derecho comunitario no se equiparan a actividades reglamentadas o sometidas a control o supervisión administrativa. Son servicios que suministran prestaciones a la colectividad, a la colectividad contemplada en su conjunto o de manera individualizada a los ciudadanos como miembros de la comunidad, y de esta prestación deriva un incremento del bienestar colectivo, generan una mayor cohesión social; por ello los poderes públicos asumen unas funciones especiales en relación a estas tareas, no las dejan al albur del mercado, sino que determinan el qué,

${ }^{28}$ Comunicación 2001/C 17/04. 
quién, cómo y con cargo a qué fondos deben realizarse determinadas misiones (de interés general). Como bien sabemos, en la actualidad el bienestar social, la cohesión son también factores de competitividad de los países.

Como ha expresamente indicado la Comisión, el concepto de servicios de interés general abarca los servicios de mercado y de no mercado que las autoridades públicas consideran de interés general y a los que imponen determinadas obligaciones de servicio público» ${ }^{29}$.

Pero la noción de servicios de interés general no aparece en el TCE ni tampoco en el Derecho comunitario derivado. Allí encontramos, por el contrario, los servicios de interés económico general. Como es sabido, a éstos se refiere explícitamente el actual artículo 86 TCE en el capítulo relativo a la disciplina de la competencia, cuyo contenido se ha mantenido invariable respecto del Tratado de Roma. Se trata de un precepto que no fue aplicado durante los primeros veinte años de funcionamiento de la Comunidad Económica Europea y que, posteriormente, la dinámica iniciada con el Acta Única (1987) y con el TUE (1992) ha colocado en el centro de la política comunitaria de construcción del mercado interior. El Tratado de Amsterdam los ha posteriormente dotado de mayor significación, de más valor situándolos entre los Principios y estableciendo que «en consideración a la importancia de los servicios de interés económico general en el ámbito de los valores comunes de la Unión, además de su papel para la promoción de la cohesión social y territorial, la Comunidad y los Estados miembros según sus respectivas competencias... prestan para que tales servicios funcionen sobre la base de principios y condiciones que les permitan la realización de sus obligaciones» (art. $16 \mathrm{TCE}$ ). Este nuevo artículo cambia la impostación de los servicios de interés económico generales. La referencia es positiva. No son ya más una excepción, constituyen un valor común en el proceso de integración.

Más recientemente, si aceptamos lo que afirma la Comisión en su relación en el Consejo Europeo de Laeken sobre Servicios de interés general ${ }^{30}$, la Carta de Derechos Fundamentales de la Unión habría establecido (?) «el acceso a estos servicios como uno de los derechos fundamentales de la Unión». En realidad la Carta no usa este concepto jurídico para caracterizar la posición subjetiva de los ciudadanos; la fórmula usada es mucho más genérica y es seguramente el resultado del equilibrio entre concepciones político-institucionales diversas. El artículo 36 de la Carta establece que «la

\footnotetext{
${ }^{29}$ Comunicación al Consejo Europeo de Laeken, Bruselas 17 de octubre de 2001.

${ }^{30}$ Comunicación (2001).
} 
Unión reconoce y respeta el acceso a los servicios de interés económico general, de la forma en que lo dispongan las legislaciones y prácticas nacionales...».

En la misma dirección se orienta el reciente Libro Verde sobre los servicios de interés general en Europa, presentado por la Comisión ${ }^{31}$. En efecto, los servicios de interés general se conciben como «pilares de la ciudadanía europea, forman parte de los derechos que asisten a los ciudadanos europeo y brindan una oportunidad de diálogo con las autoridades políticas... ayudan a ejerce efectivamente los derechos fundamentales» ${ }^{32}$.

Por lo tanto, parece pertinente preguntarse por la equivalencia entre las nociones de servicios de interés general y servicios de interés económico general.

Sin embargo, no son éstas las dos únicas expresiones que emergen en el debate actual. Como bien ilustra la pareja de conceptos que se han usado para caracterizar las diversas valoraciones de servicios públicos, existen los servicios económicos y aquellos no económicos. Dos nociones que reencontramos también en la comunicación de la Comisión sobre servicios de interés general.

¿Qué sentido tienen estas fórmulas? ¿Presentan una cierta importancia jurídica, tienen valor desde el punto de vista prescriptivo? ¿Sirven sólo para identificar realidades que luego no serán disciplinadas por normas diferentes? ¿Tienen un valor puramente descriptivo? ¿O bien la distinción es relevante ya que a cada fórmula correspondería una disciplina diversa?

La correspondencia con locuciones tradicionales es, en los distintos sistemas jurídicos de los Estados miembros, incierta. Sobre todo porque en los diversos ordenamientos jurídicos nacionales no es idéntico el modo de afrontar el papel del legislador, de la jurisprudencia o de la doctrina.

Y seguramente para comprender el significado y alcance de las nociones presentes en el TCE es fundamental tomar en consideración el dato de la diversa significación de una noción presente en muchos estados miembros, pero portadora de referencias muy heterogéneas. La integración no podía realizarse sobre conceptos propios de tradiciones jurídicas nacionales. DíEz-PicAzo ha recordado y enfatizado recientemente estos datos, «es casi seguro que la deci-

\footnotetext{
${ }^{31}$ Bruselas, 21 de mayo de 2003, COM (2003) 270.

${ }^{32}$ Ap. 3 y 4 COM (2003).
} 
sión de introducir una expresión de nuevo cuño respondió al deseo de dar vida a un concepto jurídico autónomo, propio del derecho comunitario» ${ }^{33}$.

Especialmente si atendemos al dato, muy común en el Derecho administrativo francés y en el xIX español, de que la expresión servicio público puede referirse o bien al organismo que presta de hecho el servicio o a la función de interés general atribuida al organismo correspondiente ${ }^{34}$. La integración europea requiere adoptar una perspectiva necesariamente material, éste es el ámbito de lo común, por el contrario, lo organizativo constituye la esfera donde se plasman las diversas tradiciones nacionales. Como recuerda la Comisión, «la forma en que se organizan estos servicios difiere en función de las tradiciones culturales, de la historia» 35 .

\section{LA DISTINCIÓN ENTRE SERVICIOS PÚBLICOS ECONÓMICOS Y SERVICIOS NO ECONÓMICOS, UNA DISTINCIÓN PRESENTE EN EL DERECHO POSITIVO ESPAÑOL, UNA DIFERENCIACIÓN DOTADA DE SIGNIFICACIÓN PRÁCTICA. UNA DISTINCIÓN TÍPICA EN EL DERECHO LOCAL DE LOS SERVICIOS PÚBLICOS}

\section{Los Municipios, un ámbito para la prestación de los servicios públicos}

Como es bien conocido, la irrupción de los Municipios en los servicios públicos se produce de manera desigual en los países europeos, diferencias de índole cuantitativa y también temporal, los países nórdicos y Gran Bretaña tomarán la delantera. El movimiento político del socialismo municipal que estudió en su momento PosADA suministra alguna de las claves de esta diferencia. Por ello el análisis de los servicios públicos locales siempre ha sido un campo muy fértil para examinar las transformaciones de la Administración Pública.

Ello nos permite introducir algunas precisiones que nos parecen relevantes en el marco de nuestro análisis, puede parecer una obviedad pero la lectura de distintas aportaciones doctrinales pone de relieve la falta de

\footnotetext{
33 «La idea de servicios de interés económico general» REDE, 2002, 2.

${ }^{34}$ La Comisión en su Comunicación al Consejo Europeo de Laeken ha explicitado esta problemática considerándola una factor de ambigüedad, vid. Comunicación, op. cit.

${ }^{35}$ Ap 10 Comunicación (2003).
} 
consenso en la identificación de los modos de hacer de las Administraciones Públicas.

Primera. Entendemos que para delimitar correctamente la función administrativa que denominamos servicio público es preciso contraponerla a la de policía ${ }^{36}$. No puede configurarse en abstracto al margen de las otras tareas administrativas, y en este proceso la función que se desdibuja es la de fomento (si atendemos a la trilogía tradicional). Segunda. Para comprender qué aporta la idea de servicio público a la comprensión de las tareas administrativas hay que partir del cambio sustancial que supone el hecho de la realización directa de determinadas actividades por la Administración (primero escuelas, hospitales, más tarde alumbrado, abastos...); si se parte de la concesión (que en sus inicios era de obra pública) no se pueden comprender los cambios que progresivamente y a veces sin sobresaltos se irán produciendo a partir sobre todo de finales del s. XIX. Tercera. Ello supone entender el servicio público como una forma de ejercicio de competencias ${ }^{37}$, pero una forma que sólo discrecionalmente puede ser adoptada por la corporación local (excepto en el ámbito de los denominados servicios obligatorios), una forma de ejercicio de la competencia mediante la creación del servicio público y que implícitamente implica una valoración de las insuficiencias que los poderes de policía suponen en orden a la correcta satisfacción de las necesidades la colectividad. En consecuencia, y a título de ejemplo, que el abastecimiento de aguas a poblaciones sea competencia municipal no implica necesariamente que esta actividad sea servicio público, deberemos examinar si expresa o implícitamente así se ha decidido por el municipio, lo que exige analizar con detenimiento quién suministra el servicio, el régimen jurídico al que está sometido (las obligaciones), la posición de los usuarios; y sobre todo la creación del servicio público no implica necesariamente que las actividades privadas que se desarrollan en paralelo deban estar sometidas a una reglamentación equivalente ${ }^{38}$.

\footnotetext{
${ }^{36}$ La LBRL la denomina actividad de intervención y señala los distintos medios que pueden utilizarse así como los principios que la disciplinan (art. 84).

${ }^{37}$ Es cierto que en principio ésta debería ser una cuestión pacífica puesto que el Derecho positivo local dice expresamente que son servicios públicos locales cuantos tienden a la consecución de los fines señalados como de su competencia (art. 85.1 RBRL), pero entendemos que en el momento del razonamiento inmediatamente posterior se produce un quiebro y parece entenderse como si los servicios públicos existieran ex ante, por naturaleza, al margen de la decisión municipal. Quizás esta interpretación trae causa del Decreto de 1924 que declaró servicio público el suministro de energía eléctrica, agua y gas y los sustrajo en parte a las competencias municipales, vid., por todos, E. García de Enterría: «El servicio público del gas», en Problemas actuales del régimen local, IGO, Sevilla, 1986 (segunda reedición).

${ }^{38}$ Como parece inferirse de las construcciones relativas al «servicio público impropio u objetivo», o de la afirmación de FERNÁNDEZ GonZálEZ relativa a la «restricción o limitación de la actividad de
} 
Realizadas estas precisiones, veamos ahora la cuestión relativa a la diferente naturaleza de los servicios públicos, que datos aporta el Derecho positivo.

\section{Una paleta de servicios públicos locales muy variada}

En efecto, en el Derecho administrativo español, la legislación local hace tiempo (1955) estableció una distinción entre servicios que tienen carácter económico, comercial o industrial y el resto ${ }^{39}$. En particular, la distinción opera entre aquellos que comportan el ejercicio de autoridad y aquellos relativos a las actividades de beneficencia (hoy hablaremos de servicios sociales) ${ }^{40}$. Éstos no se presentan, sin embargo, de forma homogénea y los criterios para identificarlos no han sido nunca anticipados ni por la jurisprudencia ni por la doctrina.

En realidad puede observarse cómo, una vez establecida la diferencia, sólo los servicios de carácter económico constituyen el objeto de la disciplina legal. Es decir, tanto en el pasado como actualmente los servicios sin carácter económico requerían y requieren únicamente para su creación de la voluntad del Pleno de la Corporación Local y para adoptar una decisión tan relevante desde el punto de vista de los intereses de la comunidad (financieros y sociales) aparentemente no era ni es necesario seguir procedimiento específico alguno. A tal ausencia de disciplina específica en el procedimiento no es ajena la lógica de la subsidiariedad, sobre todo en referencia a instituciones religiosas, tanto ayer como hoy presentes aún en la escuela y en los servicios sociales, si bien estos últimos se han laicizado como consecuencia de su desarrollo en el periodo democrático. Déficit de regulación relativo a la creación de servicios no económicos que se explica seguramente en clave histórica, porque toda la construcción doctrinal sobre los servicios públicos en los años cincuenta del siglo xx tenía como objetivo la garantía de la posición de los empresarios privados (frente a las ingerencias del poder), a menudo en posición de monopolio; la prestación de servicios no económicos no existía prácticamente en el panorama institucional de la época ${ }^{41}$. Además, los servicios no económi-

\footnotetext{
los particulares», La intervención del municipio en la actividad económica. Los títulos que la legitiman, Civitas, Madrid, 1995, p. 160 y p. 302. Nótese que la creación de guarderías (y antes farmacias) por el Municipio no tiene por qué suponer un cambio en la reglamentación de las privadas; y tanto una como otra actividad constituyen actividades lucrativas para los particulares.

${ }^{39}$ Art. 42 RSCL (1955), siendo el único texto normativo a nivel local que queda de aquel periodo.

${ }^{40}$ Art. 42 RSCL.

${ }^{41}$ E. Malaret: «Administración Pública y servicios públicos: la creación de una red de servicios sociales a los ancianos ...», op. cit.
} 
cos no se gestionaban nunca en monopolio, por lo que el problema del enfrentamiento con la iniciativa privada no se planteaba de manera tan radical, especialmente en el ámbito local.

En el sistema del RSCL los servicios cuya prestación exigía el ejercicio de poderes de autoridad no podían ser gestionados por privados. Posiblemente esta regulación presuponía la adhesión a la construcción dogmática de la noción de matriz doctrinal italiana función pública ${ }^{42}$. La actual legislación local (1985) ${ }^{43}$ y la legislación relativa a contratos de las Administraciones Públicas (1995) ${ }^{44}$ han conservado esta regla, generalizándola a todas las administraciones. Debe, sin embargo, señalarse que sus efectos no son satisfactorios desde el punto de vista de la seguridad jurídica, tal y como se desprende del debate surgido en torno al régimen jurídico de las inspecciones técnicas ${ }^{45}$; si bien hay que notar cómo esta regla ha impedido la encomienda a terceros de todos los servicios de recaudación, obligando a separar la gestión material del ejercicio de prerrogativas.

Y finalmente, respecto de los servicios de beneficencia, la única regla específica establecía una relación con una institución jurídica particular, el concierto; forma de gestión privada de servicios públicos que supone el recurrir a una organización privada ya existente y que desarrolla actividades análogas. Esta forma de gestión mediante organizaciones privadas surge en el ámbito de la beneficencia a finales del siglo XIX, siendo el resultado de la transformación lenta y subrepticia de relaciones de subvención - muchas de ellas vinculadas pues a la anualidad de los presupuestos y a la discrecionalidad de las transferencias de recursos públicos, así como a su carácter unilateral- en relaciones de tipo más estable y con una marcada bilateralidad ${ }^{46}$. Bilateralismo que fue normalizado y positivizado en la Ley de Contratos del Estado (1955), asumiendo definitivamente su naturaleza contractual.

\footnotetext{
${ }^{42}$ Configurada en oposición dialéctica al servicio público.

${ }^{43}$ LBR, la llei municipal i de règim local de Catalunya traduce esta idea de autoridad en términos de «ejercicio de poderes de coacción administrativa» (art. 245).

${ }^{44}$ Modificada sucesivamente hasta el nuevo texto único del 2000, Real Decreto legislativo 2/2000, por el que se aprueba el texto refundido.

${ }^{45}$ Por todos, Carrillo Donaire, El Derecho de la seguridad y de la calidad industrial, Madrid, Marcial Pons, 2000.

${ }^{46}$ Vid. el trabajo de V. Aguado: «La beneficencia: de la actividad de policía al servicio público; el caso de la Mancomunidad de Catalunya», en AAVV: Los servicios sociales a la tercera edad... op. cit.
} 
El concierto es pues uno de los tipos legales de contrato administrativo. La previsión normativa del concierto ha venido acompañada de una pérdida de especificidad porque hoy éste es la forma más generalizada en aquellos servicios vinculados directamente con las necesidades de las personas y susceptibles de prestación uti singuli (educación, servicios sociales, sanidad). Hay que destacar que a pesar de su significación y su utilización masiva no ha sido todavía objeto de atención por parte de la doctrina española ${ }^{47}$.

El amplio uso de esta fórmula no se ha acompañado con la adopción, por parte del legislador, de una disciplina jurídica adecuada y coherente con las necesidades a satisfacer, de modo que ésta aparece a menudo más como un sistema de atribución de subvenciones públicas que como prestación de servicio público, las relaciones con los usuarios adolecen de un marco legal estable y dotado de concreción suficiente.

La distinción entre servicios públicos económicos y los que no tienen este carácter se ha visto reforzada por la legislación local post-constitucional. En efecto, como consecuencia de la expresa sanción constitucional de la capacidad de los poderes públicos de intervenir directamente en la economía (art. 128.2 CE). Pero este reconocimiento que supone la supresión del principio de subsidiariedad ${ }^{48}$ ha generado en el ámbito local una cierta confusión a la que no es ajena la redacción de la LBRL (art. 86), seguramente muy influenciada por la tradición del servicio público como monopolio, ahora denominado reserva.

En efecto, este precepto parece sugerir que cuando la realización de actividades económicas por el Municipio se desarrolla en régimen de concurrencia con los particulares ${ }^{49}$, nos situaríamos al margen de los servicios públicos ${ }^{50}$; pero no es exactamente así, puesto que inmediatamente se señala que deberá contemplarse la forma concreta de gestión del servicio (art. 86.2), lo que nos devuelve inmediatamente a la óptica del servicio público.

\footnotetext{
${ }^{47}$ El único trabajo que examina los conciertos educativos y los aborda en una perspectiva claramente singularizadora, vid. J.M. Diaz Lema: Los conciertos educativos, Marcial Pons, Madrid.

${ }^{48}$ A. Rojo: «Actividad económica pública y actividad económica privada», RDM, 1984, 170-171.

${ }^{49}$ El calificativo de libre referido a un poder público parece excesivo, si bien procede sorprendentemente del RSCL.

${ }^{50} \mathrm{Y}$ así algunos sectores han interpretado que en este supuesto no estaríamos tanto en el marco de la antigua municipalización sin monopolio o lo que es lo mismo una intervención al margen de los listados de competencias tasados, sino ante una situación de equiparación total y absoluta de la actividad pública con la actividad privada que tendría como consecuencia la pérdida de relevancia de las competencias y sobre todo la desaparición del territorio como límite al ejercicio de las mismas. El art. 96 del texto refundido RL impide directamente esta interpretación, pero ésta es una disposición muy secundaria en la estructura de fuentes propia del Estado autonómico.
} 
Entendemos que en el estado actual del Derecho positivo local es posible interpretar el conjunto de actividades económicas como servicios públicos, si bien sometidos a un régimen en el desarrollo o ejercicio de las actividades notablemente distinto,

Así, por un lado, existen servicios públicos locales económicos que se pueden prestar en monopolio o reserva si se cumplen dos condiciones: a) de índole material, esto es, si incide sobre la lista de servicios declarados esenciales por el legislador estatal, y b) de índole formal, si así lo decide el Municipio (y lo aprueba la Comunidad Autónoma) Y, paralelamente existen y pueden existir servicios públicos que se prestan en régimen de competencia, esto es con pleno sometimiento a las reglas del Derecho de la competencia (que en la actualidad sólo están explicitadas en el Derecho comunitario), relativas fundamentalmente al abuso de posición de dominio y a la necesidad de justificar racionalmente la financiación pública singular ${ }^{51}$; de ahí la vieja referencia en el Derecho positivo español a los servicios públicos comerciales. En este último supuesto la única restricción de índole material es la relativa a la existencia de competencias, esto es, no cabe crear un servicio público al margen del círculo de intereses locales; lo que sucede es que la sanción constitucional del principio de autonomía local para la garantía de los respectivos intereses (arts. 137 y $140 \mathrm{CE}$ ) ha introducido un cambio sustancial en la forma de atribución de las competencias municipales ${ }^{52}$; así, debe entenderse que los municipios tienen todas las competencias necesarias para la satisfacción de las necesidades y los intereses de la comunidad vecinal que el legislador no haya atribuido al Estado o a las Comunidades Autónomas ${ }^{53}$. En línea con esta interpretación de las competencias municipales la idea de la antigua municipalización sin monopolio o lo que es lo mismo el recurrir a la categoría de la iniciativa pública en la economía para ampliar el círculo de las competencias locales carece de virtualidad ${ }^{54}$. Entendemos que de acuerdo con la posición constitucional del Gobierno y Administración municipal no cabe entender que puede optarse entre prestar servicios públicos económicos y

\footnotetext{
${ }^{51}$ Vid. un análisis muy completo y pormenorizado en el Derecho francés en el Rapport del Conseil d'État citado.

52 M. Cuchillo: «L'Espagne», en M. Troper (dir.): Intervention économique et pouvoir local en Europe. Económica, París, p. 17.

${ }^{53}$ Vid. en esta dirección también, J.L. CARRO: «El debate sobre la autonomía municipal», RAP, 1998, 147

${ }^{54}$ Por ello no podemos compartir la propuesta de FernándEZ GonZÁLEZ consistente en diferenciar el tipo de intervención municipal a partir de la distinción entre capacidad, competencia y titularidad, vid. op. cit, p. 69 y ss.
} 
ejercer la iniciativa pública, esta manera de razonar es ajena a la posición de un poder público que no puede desvincularse de las reglas que disciplinan las relaciones con los ciudadanos. Ante una necesidad colectiva apreciada como tal no cabe la opción.

En este momento del razonamiento cabe preguntarse qué operatividad tiene el configurar estas actividades económicas sometidas a la competencia como servicios públicos y no optar por una estrategia hermenéutica distinta, entendiendo que se trata de algo nuevo, distinto, suficientemente disciplinado por el Derecho de la competencia y el principio de paridad de trato que es su corolario. Entendemos que no existen elementos suficientes que permitan romper con un régimen tradicionalmente establecido en el Derecho administrativo español, puesto que el Derecho local ha admitido sin ninguna dificultad la dualidad de servicios públicos en monopolio y en concurrencia ${ }^{55}$. Como es bien conocido, un sector de la doctrina acostumbrada a presentar precisamente al ámbito de los servicios públicos locales como distinto del estatal, como algo singular (una curiosidad quizás) y la causa de la diferencia estaba precisamente en el dato de la existencia de servicios públicos prestados en régimen de concurrencia.

Entendemos que no cabe inferir del reconocimiento constitucional de la iniciativa pública en la economía la plena y completa equiparación con los particulares, puesto que ello supondría el desconocimiento de las vinculaciones a las que está sometida la Administración pública y que podemos sintetizar con las referencias al principio de legalidad (que no requiere necesariamente una interpretación como vinculación positiva), el principio del control jurisdiccional y el principio de legitimidad democrática. De la garantía de los mismos se deducen reglas más precisas que ahora no podemos desarrollar ${ }^{56}$, pero que no cabe minusvalorar.

En consecuencia, entendemos que en la esfera local poco aporta la noción de iniciativa pública en la economía. Es cierto que, como señalábamos anteriormente al referirnos a los tabacos, se hace difícil aplicar la categoría servicio público a algunas actividades desarrolladas por los municipios, pensamos en actividades vinculadas al fomento del desarrollo

\footnotetext{
${ }^{55}$ Como recuerdan los trabajos de Fernández GonZález, Díaz Lema y De la Quadra-Salcedo citados anteriormente.

${ }^{56}$ Vid. en esta dirección E. Malaret: Público y privado en la Organización de los Juegos Olímpicos de Barcelona 1992, Civitas, Madrid, 1993, y «El Derecho de la Administración pública, Derecho público y Derecho privado; la relevancia de los principios constitucionales», en AAVV: Derecho Público y Derecho Privado en la actuación de la Administración pública, Marcial Pons, Madrid, 1999.
} 
económico como, por ejemplo, establecimientos hoteleros o recreativos, palacios de congresos; por el contrario, en el ámbito estatal los ejemplos podrían ser más numerosos si bien las políticas de privatización han incidido especialmente en este campo. Pero, en estos casos, entendemos que la configuración como servicios públicos (sometidos a la concurrencia) suministra una malla legal más densa, más capaz de ofrecer respuestas ante determinadas situaciones que la huida que implica recurrir a la noción más difusa de iniciativa pública en la economía. Es cierto que el núcleo duro del régimen jurídico del servicio público difícilmente desplegará todas sus potencialidades, pero el Derecho del consumo no garantiza necesariamente la igualdad de acceso y sobre todo el Derecho de la competencia induce a una desvinculación del control democrático al sustituirlo por el control del mercado, lo que está lejos de ser suficiente en actividades fruto de decisiones adoptadas por Gobiernos democráticamente designados.

En la tradición del legislador local, los servicios que tienen carácter económico ${ }^{57}$ se hallan sometidos a una disciplina procedimental muy estricta para poderlos crear, un régimen que tiene como objetivo garantizar la oportunidad y calidad de la decisión ${ }^{58}$ y sobre todo la defensa de la libre iniciativa privada ${ }^{59}$. Esta normativa parece inducir a considerar que sólo en tales ocasiones deben valorarse los riesgos de la iniciativa, los costes de las inversiones necesarias (equipamientos), los gastos de mantenimiento y, también, el correspondiente plano financiero. Los esquemas operativos de la vieja municipalización, con o sin monopolio, subsisten a veces ${ }^{60}$ con el añadido o refuerzo de un nuevo argumento la subsidiariedad sería una exigencia misma del TCE. Se produce una confusión de planos del discurso, esto es, la exigencia de procedimiento para la creación de servicios locales significa una racionalización del proceso decisorio, una demanda de justificación fuerte, pero una decisión que necesariamente supone una elección, una valoración de la oportunidad dentro del margen de apreciación que la distribución de competencias permite.

El valor o mejor el contenido económico de ciertos servicios aparece nuevamente en las legislaciones generales sobre contratos administrativos.

\footnotetext{
${ }^{57}$ La ley local catalana se refiere explícitamente a los servicios de carácter económico (art. 238), a los servicios de naturaleza económica (art. 247.1), aquéllos que pueden ser gestionados en forma de sociedad comercial de capital enteramente público o mixto.

${ }^{58} \mathrm{Vid}$. por ejemplo art. 97 texto refundido RL.

${ }^{59}$ Como señala T. DE LA CUADRA-SALCEDO, ello no supone reconducir esta exigencia a la antigua interpretación del principio de subsidiariedad, pero si ponderar la oportunidad de la misma y los efectos que tendrá sobre la actividad privada, vid. Corporaciones locales, op. cit.
}

60 J.M. Díaz Lema: Los monopolios locales, Madrid, 1995. 
Y, también en este caso, la condición que se establece es, en mi opinión, muy significativa, si bien luego la práctica la está diluyendo ${ }^{61}$. En efecto, «la Administración podrá gestionar indirectamente, mediante contrato, los servicios de su propia competencia, siempre que éstos tengan un contenido económico que los haga susceptibles de explotación por empresarios particulares» (art. 155.1).

La referencia a la explotación económica sugiere inmediatamente la cuestión de las formas de remuneración del empresario privado. Creemos que cabe considerar que esta remuneración que necesariamente debe derivarse de la explotación no implica necesariamente que el coste de los servicios sea a cargo del usuario. Si bien no puede desconocerse como una de las formas más emblemáticas de gestión de los servicios públicos económicos, la concesión (que se gestiona bajo el principio de riesgo y ventura del empresario) supone generalmente el pago de los servicios por los usuarios de acuerdo con el régimen tarifario establecido por la Administración. Pero no sólo el pago por los usuarios incentiva una explotación económica, esto es, una eficiente asignación de los recursos, caben otros mecanismos de remuneración, lo fundamental es su vinculación con la explotación ${ }^{62}$ (sino inducen a una desincentivación de la gestión empresarial buscada con la contratación a terceros).

\section{La superposición de la acepción orgánica y funcional del servicio público, su reflejo en la caracterización de algunos organismos públicos. Una correlación entre función y organismo coherente con el principio de eficacia}

Si bien, como veíamos anteriormente, la utilización de la expresión servicio público para referirse tanto a la función o cometido asignado como a la organización que lo tiene encomendado puede inducir a confusión en el marco del Derecho comunitario, ello no es óbice para que en el ámbito del Derecho nacional la legislación establezca una cierta correlación entre el tipo de función encomendada a una organización pública y el tipo de organismo creado al efecto. Parece una opción coherente con el principio de eficacia que ha sancionado la Constitución (art. 103.1).

\footnotetext{
${ }^{61}$ De nuevo la problemática del concierto, un desarrollo en E. MALARET: «Administración Pública y servicios públicos: la creación de una red de servicios sociales a los ancianos en la transformación del Estado de bienestar», en AAVV: Los servicios sociales..., op. cit.

62 Vid. un mayor desarrollo en E. MALARET «La financiación de la televisión pública y privada», AAVV: El régimen jurídico del audiovisual, Marcial Pons, Madrid, 2000.
} 
Pero nuestro Derecho administrativo no ha ido tan allá, si bien algunos tímidos intentos podemos encontrar en el Estatuto de la empresa pública de Catalunya y la más reciente LOFAGE.

La especificidad de ciertos servicios públicos ha hallado también correspondencia en características de tipo organizativo ${ }^{63}$.

La legislación presupuestaria estableció en $1977^{64}$ una distinción entre organismos autónomos administrativos y organismos autónomos de carácter económico, comercial, industrial o financiero ${ }^{65}$ (términos de clara resonancia en la legislación local), algunos autores han señalado que con anterioridad la distinción ya estaba presente en nuestro Derecho en la normativa sectorial ${ }^{66}$. Sin embargo, no se estableció definición alguna ${ }^{67}$, ni tampoco la jurisprudencia se ha ocupado de esta cuestión dado que no ha habido ocasión como consecuencia de la ausencia de conflictos respecto de terceros. La distinción ha tenido una finalidad muy pragmática y muy limitada ya que pretende solamente incidir sobre el régimen jurídico de la contabilidad y el presupuesto. Esta legislación ha posteriormente establecido también una cláusula general, según la cual debe aplicarse el sistema de contabilidad privada cuando: «a) la actividad principal sea la producción de bienes y servicios destinados a ser vendidos en el mercado, b) el

\footnotetext{
${ }^{63}$ La introducción de la, ahora ya modificada, Ley de entidades estatales autónomas (1955) hacía referencia a los organismos autónomos que desarrollaban actividades económicas; si bien luego dicha referencia no tenía una específica traducción de tipo organizativo.

${ }^{64}$ Ley General Presupuestaria.

${ }^{65}$ Art. 145 de la Ley reguladora de las Haciendas locales, art. 85 de la Ley general presupuestaria y Ley de finanzas publicas de Catalunya.

${ }^{66}$ En esta dirección no puede olvidarse cómo la asunción directa del servicio público ferroviario supuso la creación de la primera gran organización pública española de carácter instrumental, es fácil imaginar cómo las necesidades de un tráfico jurídico en masa, la cantidad de usuarios que previsiblemente iban a utilizar el servicio obligaron en su momento a crear un tipo organizativo especial, RENFE, que en mi opinión sin afán caracteriológico alguno se configuró como entidad de Derecho público sometida al Derecho privado (la simplicidad de la definición es muy ilustrativa), las mismas características estarán presentes más tarde cuando se alumbre el tipo y la correspondiente denominación de organismo autónomo económico, comercial...Vid., sobre las razones que originaron el estatuto de RENFE, E. GarCía DE EnTERRÍA: «Estudio para un proyecto de Estatuto de RENFE», RAP, 1965, 46.

${ }^{67}$ Téngase presente que la reforma de la organización de la Administración del Estado ha comportado un cambio en la denominación de los organismos con personalidad jurídica, que ahora se llaman organismos autónomos y entidades públicas empresariales; véase en la Ley de Organización y Funcionamiento de la Administración General del Estado (1997). El Derecho de contratos se resiente por esta nueva denominación, pues no se aplica a tales organismos en vía de principio y sus contratos son de Derecho privado, sólo se aplica con carácter general a los organismos autónomos.
} 
$50 \%$ de las entradas provenga de la venta en el mercado de la producción» ${ }^{68}$. Cabe por lo tanto hablar de un criterio material como es el tipo de actividad y su finalidad o mejor aún su destino —el mercado—, y de un criterio financiero, el origen de los recursos ${ }^{69}$; dos condiciones estrechamente ligadas entre sí. En efecto, puesto que el bien o servicio va destinado al mercado, se financia con ingresos provenientes del mercado.

Esta pareja no da una idea plena de la diversidad de organizaciones públicas ${ }^{70}$, pero permite entender cómo la diversificación de las actividades se conecta también a una distinta relación con el mercado. ¿Con lucro? ¿Con aprovechamiento? ¿O tal vez con la utilidad individualmente considerada?

En este contexto podríamos considerar como servicio público económico aquel servicio que es prestado en un régimen de precio debido a título de contraprestación, un precio que trae cuenta del beneficio que obtiene individualmente del individuo. Forma de financiación que, como es notorio, tiende a hacer prevalecer el principio de eficiencia.

Esta distinción, sobre todo si tenemos en cuenta la vertiente de la financiación, permite considerar tanto las características naturales de las actividades como la opción política originaria y primaria. Es cierto que la distinción legal opera ex-post y que es, en verdad, una constatación o una consideración en atención al carácter divisible o no de la prestación, a la existencia o no de beneficiarios individuales; al uso especial o no, a un uso que excluya o no a los otros, a un uso que puede o no beneficiar especialmente a algunos. Un conjunto de condiciones a tomar en consideración y que permite a los entes locales prestar determinados servicios contra pago.

Es decir, la distinción entre servicios económicos y no económicos permite darnos cuenta de cuándo (y en qué medida) se deja una actividad a las fuerzas del mercado, a la lógica del provecho, o por el contrario cuándo (y en qué medida) se hace salir una actividad del mercado porque no se considera que sea el mejor mecanismo para la obtención de tales servicios o para obtenerlos en modo satisfactorio ${ }^{71}$. Como es sabido, la idea de

\footnotetext{
68 Art. 123 Lgp.

${ }^{69}$ La importancia del origen del los recursos aparece de nuevo en la regla general, establecida por la LOFAGE, relativa a la prohibición de financiar las entidades públicas empresariales con recursos provenientes del presupuesto del Estado (art. 65).

${ }^{70}$ Piénsese en las sociedades comerciales de capital enteramente público o mixto.

${ }^{71}$ De nuevo es preciso insistir sobre el dato que una decisión de este tipo no supone en ninguna medida que todas las actividades de similar naturaleza deban seguir el mismo régimen, los particulares pueden y deben continuar desarrollando sus actividades como mejor les parezca o con-
} 
fallos de mercado ha estado siempre presente en la erección y en la calificación de ciertas actividades como de servicio público.

Así, la distinción entre servicios públicos económicos o no supone tomar en consideración la opción política, una decisión que necesariamente irá acompañada de la definición de régimen jurídico específico; régimen destinado a permitir la satisfacción de las necesidades consideradas. Unas necesidades que obviamente no pueden satisfacerse sin coste alguno, la cuestión estriba en quién y cómo se financia, ésta es una decisión política por excelencia. ${ }^{72}$ Sobre este punto volveremos más tarde.

\section{UNA DISTINCIÓN TRADICIONAL EN EL DERECHO ADMINISTRATIVO FRANCÉS, UNA DISTINCIÓN RELACIONADA CON LA PRESENTACIÓN DOCTRINAL DE LA CRISIS DEL SERVICIO PÚBLICO ${ }^{73}$.}

A menudo encontramos autores franceses que consideran los servicios de interés económico general como un sucedáneo de la noción francesa de servicios públicos industriales y comerciales.

En efecto, en Derecho administrativo francés existe una diferencia establecida por la jurisprudencia (Bac d'Eloka 1921) entre servicios públicos administrativos y servicios públicos comerciales. Esta sentencia está en los orígenes del debate doctrinal francés sobre la operatividad del criterio de servicio público en la aplicación del Derecho administrativo, rompía la ecuación servicio público (se entiende prestado por la Administración, como era, en este caso, la colonia de Costa del Marfil) ${ }^{74}$, régimen administrativo, control del juez administrativo. El Tribunal de Conflictos entendió que puesto que «la operación de pase de peatones y vehículos se realizaba mediante el pago de una remuneración, la explotación del servicio de transporte se realizaba en las mismas condiciones que un industrial

\footnotetext{
venga, es su libertad. Y la prestación de los servicios públicos deberá realizarse de manera que no impida este desarrollo.

${ }^{72}$ Lo que en ningún momento puede significar no susceptible de sometimiento a reglas jurídicas y a control, vid. por todos, sobre esta última cuestión, G. ORón MoRATAL: La configuración constitucional del gasto público, Tecnos, Madrid, 1995.

${ }^{73}$ Por todos, A.S. Mescheriakoff, Droit des services publics, París, 1991.

${ }^{74}$ El Comisario del Gobierno Matter (uno de los grandes nombres de la época) había explicitado que la gestión era directa, insistiendo en que ello era así de manera ocasional, accidental, porque ningún empresario privado se había ocupado de ello», vid. M. Long/P. WeiL/G. Bribant/P. DeLvolvé/B. Genevors: Les grands arrêts de la jurisprudence administrative, Sirey, París.
} 
ordinario... pertenece al juez ordinario conocer de las consecuencias indemnizables del accidente evocado», como señalan autorizados comentaristas, «la innovación fundamental consistió en aplicar la noción de gestión privada a servicios públicos considerados en su conjunto, en bloque; a partir de entonces se hablará servicios públicos industriales o comerciales ${ }^{75}$. Nótese la centralidad del pago de una remuneración por parte de los usuarios en la determinación de la naturaleza y el régimen aplicable. Actualmente el criterio del objeto ya no es determinante, se opera con una variedad de criterios.

La distinción entre servicios públicos administrativos y servicios públicos comerciales tiene relevancia jurídica, dado que incide sobre la organización y el régimen jurídico. De hecho, en los servicios administrativos las relaciones para con los usuarios, aquéllas de sus empleados para con terceros, el régimen fiscal y el presupuesto, así como la contabilidad están sometidos al Derecho público; por el contrario, los servicios industriales y comerciales están por norma regulados por el Derecho privado.

En la actualidad en el Derecho administrativo francés constituye una idea pacífica la afirmación de que no existen servicios económicos o industriales por naturaleza; a diferencia de lo que ocurre en la doctrina española, dónde la noción constitucional de servicios esenciales ha supuesto la introducción de estos planteamientos ${ }^{76}$. A pesar de que inicialmente algunos autores habían intentado concebir los servicios públicos administrativos como aquellos relativos a las funciones naturales del Estado y por contra los servicios públicos industriales y comerciales cono aquellos propios de los privados y vinculados al poder público de forma accidental (como el propio comisario del arrêt Bac d'Eloka), este intento intelectual estaba destinado a no funcionar. Sin embargo, no puede olvidarse cómo esta construcción estaba presente en la obra de HAURIOU, por ello consideraba el carácter no lucrativo y gratuito del servicio público una de sus características principales ${ }^{77}$.

La evolución constante de las funciones públicas condenaba todo intento de distinción basado en algún tipo de naturalidad en desarrollo continuo. La distinción era, pues, artificial. La apreciación de las necesidades

\footnotetext{
${ }^{75}$ Les grands arrêts... op. cit.

${ }^{76}$ Vid. inicialmente F. GARRIDo Falla: Tratado de Derecho Administrativo (II) y recientemente, M. ${ }^{a}$ Yolanda Fernández García: Estatuto jurídico de los servicios esenciales en red, Madrid, INAP, 2003, p. 131 y ss.

77 Vid., recientemente, C.G. Guglielmi: «L'introuvable principe de gratuité du service» en G. Koubi/ C.G. Guglielmi (dirs.). La gratuité une question de droit?, L'Harmattan, París, 2003.
} 
fluye con el devenir histórico.

La distinción depende de las épocas y de las formas de gestión escogidas. Tal vez de las formas de financiación. El Code des communes establece una regla muy sintomática de las particularidades de los servicios públicos industriales y comerciales. No deben suponer un provecho dado que el objetivo que los justifica no es específicamente éste, sino la accesibilidad a la prestación; además, su presupuesto debe presentarse equilibrado entre gastos e ingresos, si bien no se excluye que en ciertos casos el déficit pueda ser cubierto por la colectividad local.

Considero que es útil examinar algunos de los criterios utilizados por la jurisprudencia francesa para identificar un servicio público comercial e industrial en los casos en los cuales los textos legales no se pronuncian expresamente, lo que ocurre a menudo. Criterios que luego encontramos de nuevo en la jurisprudencia del Tribunal de Justicia de Luxemburgo.

El primero de los criterios hace referencia al objeto. Para que un servicio pueda ser considerado industrial y comercial debe proporcionar una prestación similar al objeto de las actividades ejercidas por privados.

Esta idea está latente en la sentencia Höfner e Elser ${ }^{78}$ del Tribunal de Justicia, cuando asume como elemento determinante la incapacidad de los entes públicos para satisfacer la totalidad de la demanda; además, también en la sentencia Glöckner ${ }^{79}$, que expresamente entiende que las actividades del género considerado no siempre han sido ejercidas por organismos a los que se ha asignado expresamente servicios públicos ni por la autoridad pública, eventualidad ésta que puede ser recurrente pero que «no es necesario ...que sea siempre así».

De hecho, si se puede hablar de un problema de concurrencia, ello dependerá precisamente de este elemento, dado que la actividad puede ser ejercida también por particulares. Sólo cuando existan de hecho operadores privados existirá concurrencia. Y para que existan operadores privados la actividad debe ser susceptible de utilidad privada remunerada mediante precio individualizado, lo que no ocurre en muchos de los servicios públicos locales de carácter industrial (como, por ej., la limpieza y recogida de basuras).

78 TJCE, 23 abril 1991, 41/90, Höfner e Elser c. Macrotron GmbH.

79 TJCE, 25 octubre 2001, Ambulanz Glöckner. 
El segundo criterio utilizado por la jurisprudencia francesa hace referencia al funcionamiento del servicio. La parte predominante de los recursos necesarios para el funcionamiento y para las inversiones debe derivar de las tarifas pagadas por los usuarios como contrapartida de la prestación recibida. Ello excluye que la parte principal de los recursos provenga del presupuesto de la colectividad pública responsable. Razones de orden social pueden exigir tal vez que el coste real no sea pagado íntegramente por el usuario. Este criterio permite presuponer como administrativo el servicio que se haya prestado de forma gratuita o quasigratuita.

Por lo tanto, la forma de financiación es relevante para determinar la naturaleza jurídica de un servicio público. No es condición suficiente pero quizás está relacionado con el tercer criterio y, con carácter más general, con las características del régimen jurídico.

El tercer criterio se refiere a las modalidades de gestión del servicio. Éstas deben ser lo más parecidas posibles a aquéllas que se encuentran en las empresas privadas. Reaparece con fuerza el tipo de contabilidad, las relaciones entre el personal y los usuarios. Este criterio debe ser puesto en relación con los anteriores, porque considerado aisladamente no goza de la suficiente relevancia; ello, de hecho, reenvía a los aspectos del régimen jurídico. Una cierta circularidad está, de todos modos, presente.

En todo caso, hay que señalar que el juez no tiene por qué respetar la calificación establecida en el texto, ésta puede ser engañosa, el juez examina la verdadera naturaleza del servicio. Ello le permite disociar la calificación de organismo que realiza el servicio y las funciones aseguradas, algunos organismos esencialmente administrativos (como las Corporaciones locales) pueden explotar también servicios industriales y comerciales, pero también le permite evitar calificaciones que sólo pretenden «escapar de los principios rigurosos de la contabilidad pública» ${ }^{80}$.

A veces se encuentran otras tipologías, servicios administrativos ${ }^{81}$, servicios culturales, servicios sociales, servicios económicos, son clasifica-

\footnotetext{
${ }^{80}$ De nuevo Les grand arrêts... op. cit.

${ }^{81}$ Idea muy próxima al principio que en el Derecho comunitario conduce a la exclusión de la aplicación de las normas sobre la concurrencia a los servicios relativos a prerrogativas intrínsecas del Estado, TJCE, 19 enero 1994, Sat Fluggesellschaft GmbH c. Organisation européenne pour la sécurité de la navigation aérienne (Eurocontrol).
} 
ciones de tipo funcional que sirven para evidenciar la diversidad de los servicios públicos pero que no tienen valor jurídico.

\section{LA DISTINCIÓN EN EL DERECHO COMUNITARIO Y SU VINCULACIÓN CON UNA APELACIÓN DEL TJCE A LA LEGITIMACIÓN DEMOCRÁTICA NACIONAL}

El examen de la jurisprudencia del Tribunal de Justicia de la Comunidad (y del Tribunal de primera instancia) muestra la dificultad para identificar con criterios precisos y objetivos qué debe entenderse por servicio de interés económico general.

No nos interesa, en esta sede, rehacer un camino que ya ha sido reconstruido en numerosos estudios. Es preciso subrayar que, como ya hemos visto, es fundamental que exista una decisión de los poderes públicos de imponer una obligación de gestionar un servicio de interés económico general o una prestación de servicio público, asignación de la misión de interés general que puede proceder de las autoridades de distinto nivel nacional ${ }^{82}$, encomienda que puede realizarse a una empresa pública o privada (ésta es una cuestión irrelevante desde el punto de vista del Derecho comunitario); es pues una valoración política la que está en el origen de la decisión sobre las necesidades que el propio servicio está destinado a satisfacer. Así como la decisión relativa al modo de satisfacerlos. En definitiva, el rasgo fundamental es que exista una obligación legal de desarrollar una determinada actividad, de suministrar una prestación determinada y que esta obligación sea el resultado de un acto del poder público.

Seguramente uno de los principales problemas hace referencia al sentido que el término económico tiene en la locución. De hecho y ante todo, no se comprende si es el interés o el servicio lo que se califica como económico.

En el primer sentido se trataría de servicios cuyas prestaciones de tipo — podríamos decir — horizontales serían prestadas a todas las actividades económicas: idea ésta que está muy próxima a aquélla que concentra la atención sobre las infraestructuras, con la conciencia del papel central que éstas ocupan con respecto a los fines del desarrollo económico. Por el con-

\footnotetext{
${ }^{82}$ La centralidad de la encomienda de una carga u obligación ha sido destacada por la mayoría de la doctrina, vid., por todos, M. BAzex: «L'appréhension des services publics par le droit communautaire», RFDA, 1995, 2.
} 
trario, la jurisprudencia parece más bien orientarse hacia otra dirección, la de calificar como económico el servicio. Esta orientación deriva de una interpretación sistemática del artículo 86 del TCE, en virtud de la cual la primera condición para la aplicación de dicho precepto es que refiera a una empresa. Por lo tanto, el hecho de la calificación como empresa nos llevaría a calificar la actividad correspondiente como servicio de interés económico general. Como ha precisado DíEz-PicAzo, se trata «no sólo de aquellas actividades que conforman la infraestructura del sistema económico, sino que pueden serlo también aquellas actividades cuya finalidad primaria no sea empresarial siempre que se produzcan dentro del sistema económico. Lo decisivo no es la presencia o ausencia de ánimo de lucro» ${ }^{83}$.

El problema radica, pues, en la identificación de los criterios que permitan caracterizar a la empresa. El Tribunal no ha aceptado el criterio del lucro como, de hecho, demuestra la sentencia Höfner e Elser sobre el servicio alemán de empleo con carácter gratuito.

Por empresa en el sentido comunitario, precisión definitoria necesaria para la interpretación uniforme del Derecho comunitario, se entiende «cualquier unidad que ejerce una actividad económica con independencia de su estatuto jurídico».

Si ello fuera cierto, el problema pasaría a ser el de identificar qué es actividad económica. Y es aquí donde hallamos, como criterio que opera en sentido contrario, la solidaridad (sentencia Poucet e Pistre ${ }^{84}$ ). En este sentido los entes encargados de la gestión de los regímenes de previsión social impuestos por el Estado (como la aseguración obligatoria por enfermedad) que se basan sobre este principio de solidaridad y cuyas prestaciones no son proporcionales al importe de las contribuciones obligatorias, desarrollan funciones de carácter exclusivamente sociales y no ejercen actividad económica.

Atendiendo a esta aproximación, las normas relativas al mercado interior y a la concurrencia no se aplican con carácter general a las actividades no económicas y, por tanto, no se aplican tampoco a los servicios de interés general en la medida en que se trate de actividades no económicas ${ }^{85}$. Sin embargo, los desarrollos jurisprudenciales no son tan sencillos.

\footnotetext{
83 Op. cit., p. 252.

84 Tribunal de Justicia Ce, 17 febrero 1993, Poucet c. Assurances générales de France así como Pistre c. Caisse autonome nationale de compensation de l'assurance vieillesse des artisans.

85 Comunicación 2001/C 17/04, cit.
} 
Dos sentencias deben, en mi opinión, tomarse en consideración. Glöckner y Albany ${ }^{86}$, que expresan con claridad una orientación ya tímidamente apuntada por la jurisprudencia del Tribunal de Justicia. Según ambas sentencias, en primer lugar es preciso considerar los entes como empresa y luego es necesario dilucidar qué misión de interés general a ellos confiada permite derogar las reglas de la competencia. Una misión que, para ser ejercida, debe definirse con precisión por el poder público y que exige para su ejecución un determinado régimen jurídico, una disciplina de derogación del régimen jurídico ordinario de las actividades económicas privadas. Por lo tanto, hay siempre una comparación con la actividad desarrollada por los privados y este paralelismo es lo que permite afirmar que se trata precisamente de servicios de interés económico general que se contraponen a los servicios que carecen de este carácter económico.

La simplicidad de este tipo de argumento oculta el problema real, esto es, la no identificación por parte del Tribunal de los criterios de economicidad de la actividad. Y ello permite a su vez entender la relevancia del reenvío de la determinación del interés general a la decisión nacional.

El Tribunal sostiene que son los Estados miembros las autoridades competentes para valorar (o mejor, para tomar una decisión sobre) cuando deba existir un servicio de interés económico general. Poder que se caracteriza intrínsecamente como discrecional, o también, como afirma la Comisión, como una «libertad de definición». Una discrecionalidad que está por tanto sujeta sólo a un control circunscrito a los supuestos de error manifiesto.

Este poder de los Estados miembros de definición o determinación tanto en el ámbito nacional, regional o local, no lo es sin límites, dado que está sometido al control de la Comisión y luego del Tribunal de Justicia. Y sobre todo la centralidad de este control deriva del hecho de que determina una obligación para el Estado miembro de argumentar, motivar, explicar las razones de su elección. Las necesidades de los ciudadanos, la necesidad de cohesión social o de desarrollo sostenible deben ser coherentemente expuestas, argumentadas y discutidas, ya que están sometidas a control externo, por más que éste sea limitado.

La diversidad de construcciones nacionales ha hecho difícil, si no imposible, la adopción de criterios claros y precisos para calificar los servicios de interés económico general. Esto explica la búsqueda de un nuevo equi-

\footnotetext{
${ }^{86}$ Tribunal de Justicia Ce, 21 septiembre 1999, Albany international c. Stichting bedrijfspensioenfonds textielindustrie.
} 
librio entre Comunidad y Estados miembros, lo cual se refleja con claridad tanto en el artículo 16 TCE como en el principio de subsidiariedad.

El análisis comprensivo de la jurisprudencia del Tribunal de Justicia muestra cómo las actividades no vienen consideradas por su naturaleza como servicios de interés económico general. Es la atención a su régimen jurídico, a un conjunto de indicios, a un espectro de criterios relacionados entre sí lo que permite concluir que la organización en cuestión tiene el carácter de empresa y, si los poderes públicos le han encomendado una misión de interés general, entonces nos encontraremos ante una empresa que gestiona un servicio de interés económico general.

Del análisis de la jurisprudencia comunitaria podemos inferir los rasgos que caracterizan este régimen jurídico singular, estos condicionantes que suponen una especificidad en relación a la posición de otros operadores. Los elementos que entendemos se destilan de la jurisprudencia son los siguientes: a) la obligación de ejercer una actividad más allá de las condiciones de provecho, y por tanto la exigencia de una cierta continuidad, b) la obligación de ejercer la actividad atendiendo a modalidades precisas, a menudo vinculadas a una determinada financiación y, por tanto, igualdad de acceso.

Estos elementos permiten entender el fundamento de la competencia de los Estados, esto es, de la atribución, en el actual nivel de integración, de un poder de elección u opción política a nivel nacional. La elección cubre así diversos aspectos directamente relacionados.

En primer lugar, el juicio sobre la inadecuación del mercado; una inadecuación que puede expresarse sólo con relación a las necesidades que están representadas en el proceso político, esto es, las necesidades que sean necesariamente valoradas y juzgadas como tales por la autoridad democráticamente legitimada.

En segundo lugar, estas necesidades no satisfechas por el mercado deben ser financiadas de algún modo. La elección del modelo de financiación se hace necesaria. Los modelos son conocidos, pero están siempre bajo continua discusión. Por parte de los ciudadanos mediante impuestos, esto es, con recursos públicos. Por parte de los usuarios a través de las tarifas y, en este caso, si hay un monopolio, ello permite financiar a algunos usuarios los servicios prestados al resto. Por parte de las empresas mediante un fondo (como por ejemplo el servicio universal de telecomunicaciones), lo que en realidad reenvía a una financiación indirecta por parte de los usuarios. 
En tercer lugar, los instrumentos mediante los cuales se impone la obligación. Un contrato si la dimensión de la actividad encomendada es amplia; contrato que puede adoptar diversas formas. Así, en Derecho administrativo español, concesión y concierto, y en particular la alternativa dependerá de quién paga el servicio prestado: si los usuarios, entonces concesión; si la Administración, entonces concierto (aunque existen también otras formas). Normalmente cuando la obligación es muy precisa y puntual pueden usarse instrumentos de tipo unilateral, la más típica, la autorización (siguiendo la técnica bien conocida del condicionamiento); la sentencia Analir ${ }^{87}$ y la disciplina jurídica del cabotaje ilustran bien estas posibilidades de elección diversas.

El contenido de la misión jurídica, justificación de los servicios de interés económico general, debe ser necesariamente abierto, evolutivo y variable como mudables y distintas son las necesidades del desarrollo social, económico y tecnológico. Esta idea aparece con fuerza en el reciente Libro Verde anteriormente citado.

«Una de las principales responsabilidades de las autoridades públicas ha sido siempre velar por la cobertura de las necesidades colectivas y cualitativas básicas ...Esta responsabilidad sigue siendo de una importancia capital» ${ }^{88}$.

\section{LA INFLUENCIA DE LA JURISPRUDENCIA COMUNITARIA SOBRE LOS DERECHOS NACIONALES: LA EMERGENCIA DE UNA NUEVA ARTICULACIÓN DE LOS INTERESES GENERALES (O COLECTIVOS) Y LA LIBERTAD DE EMPRESA}

Los procesos de integración europea y de construcción del mercado único han conferido un papel relevante a los denominados señores del Derecho comunitario, los jueces del Tribunal de Justicia. Su jurisprudencia, que privilegia los criterios teleológicos, proporciona muchos apuntes para repensar los Derechos nacionales, para reinterpretar las leyes fundamentales a partir de una aproximación distinta, con una impostación más pragmática de los problemas, privilegiando un método más realista y menos dogmático. Partiendo de hechos reales y, por tanto, de necesidades concretas.

\footnotetext{
${ }^{87}$ TJCE, 20 febrero 2001, Asociación profesional de empresas navieras de líneas regulares (Analir) c. Administración general del Estado.

${ }^{88}$ Libro Verde, op. cit., ap. 22 y ss.
} 
Hemos visto la importancia de las argumentaciones cuando se trata de proceder a la derogación de las reglas de la concurrencia. Debe, además, recordarse también la obligación de motivar, de justificar, norma que encontramos también en otros campos como por ejemplo el de la reglamentación técnica nacional. Motivación que constituye la regla general de los actos comunitarios y que, en esta búsqueda de un nuevo equilibrio, se traspone en obligación para las autoridades nacionales cuando pretenden adoptar una determinada regulación. Las autoridades nacionales deben justificar la necesidad y la proporcionalidad de las medidas adoptadas ${ }^{89}$.

A menudo, la lectura de las sentencias del Tribunal de Justicia muestra cómo determinadas soluciones nacionales que permanecen desde hace tiempo están en la actualidad privadas de una fuerte justificación de la intervención pública. Intervención que se explica en clave de tradición, de permanencia de soluciones adoptadas en el pasado - y coherentes con las necesidades del momento-, pero que no da ya respuesta a las exigencias actuales. Y es este peso de las respuestas de un momento pasado lo que ha impregnado las construcciones teóricas, las concepciones jurídicas más complejas. Fenómeno éste que es especialmente notorio en algunas construcciones españolas del servicio público.

La construcción comunitaria del mercado ha significado liberalización de los movimientos de capital, de los bienes y de los servicios y este proceso de apertura de los espacios nacionales exige una nueva identificación de las necesidades, no sólo en consideración a los distintos contextos de descentralización territorial de la esfera pública, sino sobre todo por el hecho de que la diversidad y la complejidad de las situaciones subjetivas, las necesidades de los ciudadanos y de las empresas y organismos non profit crecen a un ritmo veloz.

No se trata de comunitarizar el Derecho público nacional, sino de repensar las categorías jurídicas fundamentales en este nuevo contexto. Hoy sabemos que es difícil si no imposible, concebir algunos institutos de nuestro Derecho administrativo como si se tratase de un modelo autárquico. El Derecho comunitario y el Derecho de la OMC penetran en los contratos de la Administración, los servicios públicos, las ayudas, los bienes públicos. Más recientemente también la actividad de policía comienza a recibir este influjo.

\footnotetext{
${ }^{89}$ Sobre la importancia del principio de proporcionalidad, vid. por todos el estudio sistemático de L. Moral Soriano: «Proporcionalidad y servicios de interés económico general», REDE, 2002,3 .
} 
La permeabilidad de los Derechos nacionales crece, como crecen también los movimientos de las personas, de las empresas, de las asociaciones.

Paralelamente a esta europeización del Derecho administrativo, en el ordenamiento jurídico español así como en la doctrina jurídica se observa un movimiento de constitucionalización del Derecho administrativo. Constitucionalización que en el ordenamiento español pasa por la fuerza expansiva de los derechos fundamentales, y obviamente por la protección de la dignidad de la vida humana. Obligación de protección que comporta obligaciones positivas para todos los poderes públicos y especialmente para la Administración ${ }^{90}$. Constitucionalización del Derecho administrativo que corre paralela a la europeización.

Sobre estas dos bases podemos reconstruir el discurso relativo a los servicios públicos, partiendo de los derechos y libertades, de las necesidades que son exigencias, en una sociedad ordenada — retomando la fórmula de Rawls- , de la vida en comunidad y de la dignidad humana. Reconstrucción del discurso que debe necesariamente partir de la realidad que supone la diversidad de los servicios públicos y de la heterogeneidad de las formas de prestación.

Ello presupone no sólo un nuevo servicio público (atento a las necesidades de los ciudadanos y no sólo a la competencia entre agentes económicos), sino una teoría capaz de responder a la una diversidad de servicios que ha existido siempre pero de la que la doctrina no ha considerado necesario ocuparse. Especialmente cuando el contexto político-institucional español no permitía la emergencia de la pluralidad.

Todo ello implica que el perímetro de servicio público es variable, y de hecho éste ha sido precisamente el gran cambio de los últimos tiempos. Las actividades que eran servicios públicos y se ejercían en régimen de monopolio han sido plenamente liberalizadas y tendencialmente expuestas a la concurrencia. En cambio, otras actividades emergen como nuevos servicios públicos confiados a la responsabilidad de los poderes públicos y algunas de ellas no tienen nada que ver con la competencia, dado que ni el mercado ni la familia están en situación de satisfacer adecuadamente las

\footnotetext{
${ }^{90}$ La significación de los servicios públicos como garantía de los derechos constitucionales en C. CHinchilLa: «El servicio público, ¿una amenaza o una garantía para los derechos fundamentales? Reflexiones sobre el caso de la televisión», en AAVV: Estudios sobre la Constitución española (Homenaje al Profesor E. García de Enterría), Madrid, Civitas, 1991 y E. MaLARET: «Servicios públicos, funciones públicas, garantías de los derechos de los ciudadanos: perennidad de las necesidades, transformación del contexto», RAP, 1998, 145.
} 
nuevas necesidades. No puede olvidarse que la existencia de la competencia está directamente relacionada con la posibilidad de obtener provecho en el ejercicio de la actividad, esto es, con la iniciativa empresarial privada. Y ésta no siempre existe.

Este pluralismo de los servicios públicos, manifestado con claridad a través de la distinción analizada, servicios públicos económicos y servicios no económicos, exige una diversidad de formas de gestión y de financiación. Por tanto, el papel del mercado y de la competencia deberá ser necesariamente diferente.

La intervención pública, que deriva de la decisión de crear un servicio público, no ha sido nunca indiferente al mercado ni a las reglas que lo disciplinan, esto es, a las reglas de la competencia. El hecho es que la valoración de los fallos del mercado cambia con el tiempo, como cambia también la percepción de aquello que debe prestar directamente el sector público. Además, no podemos olvidar que las transformaciones tecnológicas y el desarrollo de la ciencia económica han permitido poner a punto nuevos instrumentos de regulación y nuevas técnicas que permiten el incremento de la eficiencia y la garantía de la equidad. La toma de conciencia de la escasez de recursos ha aumentado y con ello la exigencia de una diversidad en los modos de regulación.

Esta nueva forma de valorar el contexto, en la que necesariamente deben moverse los servicios públicos para lograr el cumplimiento de las misiones que a ellos se han encomendado, permite articular mediante distintas formas la relación entre el interés general (fórmula que sintetiza las diversas libertades y las distintas necesidades en juego) y la libertad de empresa, pues se trata de servicios de interés económico general.

Libertad de empresa prevista en diversas Constituciones europeas pero infravalorada hasta tiempos recientes; su funcionalización respecto del interés general la había privado de toda fuerza jurídica en el plano de su exigibilidad. Una nueva articulación de los derechos es ahora posible por obra de la obligación asignada al legislador estatal o subestatal de hacer coexistir el interés público con la libertad de empresa. Esta nueva orientación comporta la exigencia de justificar la intervención pública y de someterla a un control de proporcionalidad en sentido amplio. Por lo cual el monopolio, los derechos exclusivos o especiales deben someterse al test relativo a la adecuación constitucional de las intervenciones públicas en confrontación con los derechos fundamentales. El tipo de intervención que resulta de esta articulación se somete a un control relativo al tipo y forma de encomienda del servicio público u obligación de interés general. 
Un control que no es exclusivamente de patrón comunitario, sino también constitucional. Un control que, para no alterar las relaciones entre jueces y legislador, no debe ir más allá del control realizado por los jueces comunitarios, y ello exige que sea rigurosamente justificada la intervención pública así como su importancia. El interés general no cubre cualquier necesidad, sino más bien sólo aquéllas que encuentran un fundamento en los principios y los valores constitucionales, por lo que las medidas adoptadas deben ser adecuadas, necesarias y proporcionales a los fines que las legitiman.

En esta dirección, es preciso redefinir el instituto de la concesión y concebirlo no tanto como una barrera de entrada, como un mecanismo que habilita para ejercer una actividad que de otro modo estaría prohibida, sino como una de las formas de prestación de los servicio públicos. Una forma contractual caracterizada por la remuneración del empresario que ejerce la actividad confiada por el poder público; remuneración vinculada al rendimiento del ejercicio y a la financiación por parte de los usuarios esencialmente. Los modelos de encomienda del servicio público o de obligaciones específicas pueden ser diversos, como el Tribunal de Justicia ha evidenciado en la sentencia Analir.

Esta aproximación implica que las elecciones concretas adoptadas por el legislador (o por la Administración por remisión) pueden configurar diversas situaciones. Así, a) excepcionalmente el monopolio, de gestión pública o confiado a una empresa privada, b) en el caso de los derechos exclusivos o especiales; un número de operadores limitado pero no concurrentes entre ellos, c) competencia plena y absoluta con la designación de uno o varios proveedores del servicio universal determinado, y en su caso con la eventual compensación del coste neto que entrañe la prestación.

Y cuando por razones de equidad social o por otro tipo de consideraciones (medioambientales, seguridad, escasez de recursos...) no sea posible la concurrencia en el mercado, entonces quizá sea preciso organizar la competencia para acceder al mercado. No puede desconocerse que la competencia suministra información (sobre costes, sobre calidades...) y ello redunda en una mejor asignación de los recursos al permitir una mejor elección.

Pero para que haya efectivamente concurrencia en el acceso mercado no basta un procedimiento de concurso o competencia, que permita efectivamente la confrontación de las diversas propuestas. Es necesario sobre todo que la autoridad pública tome conciencia del papel de la concurrencia en la correcta asignación de los recursos. La eficiencia en la asignación de los recursos debe estar al servicio de la adecuada satisfacción de las 
necesidades. A tal fin es preciso tener en consideración el tiempo y el espacio, para así excluir, por ejemplo, que la duración del contrato acabe por comprometer los efectos competitivos del proceso concursal.

En relación con ello, un efecto evidentemente anticoncurrencial, que por tanto no conlleva eficiencia, lo encontramos en la legislación española sobre transportes, establece como principio general una duración mínima de las concesiones de seis años y, lo que aún nos parece más sorprendente, el carácter exclusivo de las mismas ${ }^{91}$. En particular, en el sector de los transportes urbanos, las esternalidades negativas, que se hallan en la raíz de la única norma del Tratado que refiere explícitamente al servicio público (art. 73 del Tce), han dado lugar a experiencias de concurrencia para el mercado, alternativas a la competencia en el mercado, caracterizadas por contratos de escasa duración ( $2 / 3$ años) y relativos a ámbitos territoriales que, además de estar circunscritos, coinciden en características (tamaño de la población o del territorio) con aquellos confiados a otros operadores de modo que sea posible compara los costes.

Por lo tanto, una escala de niveles de concurrencia diversificados. Una diversidad de situaciones concurrenciales que exigen un papel mucho más activo de las autoridades garantes de la concurrencia, ya sea en fase de organización del servicio o en fase de encomienda y desarrollo del mismo.

\section{A MODO DE CONCLUSIONES}

La esfera local ha propiciado históricamente un campo muy fructífero para la innovación en la gestión pública, los primeros servicios públicos aparecen normalmente en este ámbito. Por ello es aquí dónde se plantea la compatibilidad entre servicios públicos y actividad (económica o no) privada y la respuesta ha sido siempre favorable a la compatibilidad y en su caso el legislador ha sancionado la regla de la concurrencia que cuando de servicios públicos económicos se trata debe entenderse en sentido fuerte, como competencia en el mercado.

La esfera local ha presentado históricamente una especificidad en materia de servicios públicos, esto es el sometimiento a control judicial de las decisiones relativas a la creación de los mismos; si bien el juez español no parece haber tenido demasiado trabajo en este campo. En todo caso, la diferente posición del legislador suministra alguna de las razones de esta especificidad.

${ }^{91}$ Art. 72 de la Ley de ordenación de los transportes terrestres (última modificación del 2000). 
El conjunto de actividades económicas que desarrollan las Corporaciones locales (directa o indirectamente) deben ser consideradas como servicios públicos, si bien sometidos a un régimen en el desarrollo o ejercicio de las actividades notablemente distinto. Así, por un lado, existen servicios públicos locales económicos que se pueden prestar en monopolio o reserva si se cumplen las condiciones, y, paralelamente existen y pueden existir servicios públicos que se prestan en concurrencia y en su caso en competencia.

Los servicios de interés económico general constituyen la noción comunitaria que, vista su caracterización necesariamente funcional, expresa la realidad de una actividad empresarial, gestionada por un ente público o privado (en este supuesto por encomienda de la Administración pública), que está sometida al interés general y a reglas de distinta consideración en orden a su relación con el mercado y con la disciplina de la competencia.

Los servicios de interés económico general se presentan, por su parte, como el resultado de un nuevo equilibrio entre mercado único y legitimidad democrática, como un diálogo entre autoridades nacionales e interés general europeo.

La noción comunitaria de servicio de interés económico general permite reconsiderar integralmente la relación entre la protección de los derechos que reclaman una actividad positiva por parte de los poderes públicos y los derechos de libertad. Sin olvidar que también estos últimos reclaman la adopción de mecanismos institucionales adecuados a su protección.

Los servicios de interés general, sean o no económicos, presuponen un juicio de oportunidad por parte de la autoridad dotada de legitimidad democrática, en orden a las necesidades susceptibles de ser satisfechas por las prestaciones que constituyen el objeto del servicio, y es precisamente sobre la base de tal juicio que éstas deben prestarse a la colectividad

Servicios de interés general en el ordenamiento comunitario que en su trasposición al Derecho administrativo español encuentran en la noción o categoría jurídica de servicio público la expresión precisa de una cierta distribución de obligaciones y derechos, así como de las relaciones entre los poderes de la Administración y los poderes y sujeciones de los productores/ operadores (públicos o privados) del servicio. Servicio público que es precisamente la construcción que permite identificar los servicios de interés general y por tanto someterlos a un régimen jurídico especial. 
La identificación de una pluralidad de servicios públicos, de una diversidad de formas de prestación y de financiación no debe hacer perder significado a la categoría jurídica del servicio público. La diversidad de régimen jurídico, ya sea desde el punto de vista del papel de la competencia que del sometimiento al Derecho administrativo, no debe hacernos perder de vista que el núcleo esencial del régimen jurídico se organiza en torno al dualismo conceptual, ya ampliamente conocido de obligaciones y derechos.

El juicio de la autoridad, por el cual se valora el interés general respecto del cual la actividad se desarrolla, las insuficiencias del mercado o de la iniciativa privada, determina la encomienda de la misión de servicio público y hace a la misma debida y conveniente. Esto es, el acto o contrato imponen al operador la obligación de desarrollar una actividad y de realizarla según las condiciones de tiempo, cantidad y precio establecidas por el poder público responsable. Correlativamente a esta obligatoriedad de la actividad encontramos también derechos de los usuarios, es decir, los derechos de acceso a las condiciones predeterminadas por la autoridad. Obligaciones del operador y derechos de los usuarios concretan de este modo los principios típicos del servicio público, que pueden ser sintetizados con la idea de continuidad e igualdad. Principios que hallan su fundamento y su límite en el interés general que disciplina la actividad.

El nuevo equilibrio entre necesidades colectivas y libertad económica privada no se establece sólo en el ámbito de creación de los servicios públicos económicos sino también respecto de su funcionamiento.

La articulación de los valores de equidad y eficiencia exige un permanente rediseño de las modalidades de intervención pública para que ésta tenga mayores probabilidades de ser útil. 